\title{
Lipid production in association of filamentous fungi with genetically modified cyanobacterial cells
}

\author{
Ana F. Miranda, Mohamed Taha, Digby Wrede, Paul Morrison, Andrew S. Ball, Trevor Stevenson \\ and Aidyn Mouradov
}

\begin{abstract}
Background: Numerous strategies have evolved recently for the generation of genetically modified or synthetic microalgae and cyanobacteria designed for production of ethanol, biodiesel and other fuels. In spite of their obvious attractiveness there are still a number of challenges that can affect their economic viability: the high costs associated with (1) harvesting, which can account for up to $50 \%$ of the total biofuel's cost, (2) nutrients supply and (3) oil extraction. Fungal-assisted bio-flocculation of microalgae is gaining increasing attention due to its high efficiency, no need for added chemicals and low energy inputs. The implementation of renewable alternative carbon, nitrogen and phosphorus sources from agricultural wastes and wastewaters for growing algae and fungi makes this strategy economically attractive.
\end{abstract}

Results: This work demonstrates that the filamentous fungi, Aspergillus fumigatus can efficiently flocculate the unicellular cyanobacteria Synechocystis PCC 6803 and its genetically modified derivatives that have been altered to enable secretion of free fatty acids into growth media. Secreted free fatty acids are potentially used by fungal cells as a carbon source for growth and ex-novo production of lipids. For most of genetically modified strains the total lipid yields extracted from the fungal-cyanobacterial pellets were found to be higher than additive yields of lipids and total free fatty acids produced by fungal and Synechocystis components when grown in mono-cultures. The synergistic effect observed in fungal-Synechocystis associations was also found in bioremediation rates when animal husbandry wastewater was used an alternative source of nitrogen and phosphorus.

Conclusion: Fungal assisted flocculation can complement and assist in large scale biofuel production from wildtype and genetically modified Synechocystis PCC 6803 strains by (1) efficient harvesting of cyanobacterial cells and (2) producing of high yields of lipids accumulated in fungal-cyanobacterial pellets.

Keywords: Biofuel, Bioremediation, Flocculation, Fungi, Genetic modification, Renewable energy, Synechocystis PCC 6803, Wastewater treatment

\section{Background}

Growing interest in the production of clean, renewable and sustainable energy has stimulated unprecedented interest in producing new generations of renewable feedstocks for biofuel product ion including plants, microorganisms and algae, tailored for composition of essential

*Correspondence: aidyn.mouradov@rmit.edu.au

School of Applied Sciences, Royal Melbourne Institute of Technology University, Bundoora, VIC 3083, Australia molecules that can be directly used or be converted into petrochemicals.

Microalgae have obvious advantages in the production of biodiesel and value added chemicals compared to plants, yeast and microorganisms including: (1) high growth rates (can double biomass every $8-12 \mathrm{~h}$ ); (2) ability to produce substantial amounts of storage triacylglycerols (TAG)/lipids; (3) ability to grow in seawater, brackish water and wastewaters; (4) their application for efficient bioremediation of different types of wastewaters 
(animal, municipal and mining wastewaters) by removing main nutrients, $\mathrm{C}, \mathrm{N}, \mathrm{P}$, heavy metals and microelement's contaminations; (5) lack of competition with agricultural crops for arable lands; (6) no need for costly feedstocks such as reduced sugars (compare to heterotrophic microorganisms such as E. coli and yeast); (7) less labour required for their production; (8) their growth is less affected by seasonal changes in climate; and (9) their production is easy to scale [1-14].

Cyanobacteria share the same advantages as microalgae, however, unlike microalgae they do not accumulate triacylglycerols (TAGs) and their photosynthetic membranes are made of diacylglycerols (DAGs, including monogalactosyl diacylglycerols, digalactosyl diacylglycerols, phosphatidylglycerols, and sulfoquinovosyl diacylglycerols) $[15,16]$. Their lipid biosynthetic metabolism is robust and does not require environmental stresses, such as starvation for redirecting of carbon flow into fatty acids production [8-10, 17-19].

In spite of the obvious advantages there exist fundamental barriers to the industrial production of biofuels from both of these microorganisms. The major challenges include: (1) high harvesting cost; (2) a sustainable and renewable nutrient supply; (3) improvement of oil content and composition; and (4) high cost of lipid extraction $[4,5,7,10,11,14,20-22]$.

Fungal-assisted bio-flocculation can address most of these challenges [23-30]. It is highly efficient, and does not require added chemicals and has a low energy input requirement. Application of alternative sources of carbon from lignocellulosic wastes, nitrogen and phosphorus from wastewaters for fungal and algal growth improves the economics of biofuel production [27, 28, 31]. Secretion of a family of hydrolytic enzymes by fungal species can convert some microalgal species into the cell-wallfree protoplasts that can in turn reduce the requirements for organic solvents used for lipids extraction [27, 28].

We recently screened 33 fungal strains isolated from wastewater sludge for their lipid content and flocculation efficiency against 15 photosynthetic microalgae: photoautotrophic and heterotrophic, freshwater and marine, unicellular and multicellular, small $(5 \mathrm{~mm})$, large (over $300 \mathrm{~mm}$ ), motile and non-motile [27, 28]. Some of these associations showed synergistic effects on biomass production and lipid yield. Analysis of fatty acid composition of fungal-microalgal pellets suggested that they can be tailored and optimised by co-cultivating different microalgal and fungal representatives.

Natural symbiosis between fungi and microalgae/ cyanobacteria, known as lichens, have existed since plants evolved from green algae more than 400 million years [32]. More than $20 \%$ of existing fungal species are known to be lichenized and in an obligate mutualistic association with photoautotrophic green algae, cyanobacteria, or both types of photobionts [33].

Unicellular cyanobacteria, Synechocystis PCC 6803, has been considered a feedstock for renewable and sustainable energy production because of its potential for largescale biomass production due to fast growth rate, high lipid content, ability to be genetically transformed, and robustness towards a wide range of environmental conditions (including salt concentration, $\mathrm{pH}$, temperature, UV light, and carbon dioxide level) [8-10, 17-19, 34-38]. Production of thylakoid membranes in Synechocystis is not induced by environmental or nutritional stressors and is only dependent on their biomass-production rate [19, 39].

The wild-type strain of Synechocystis PCC 6803, (SD100) has recently been genetically modified using two distinct strategies designed to release free fatty acids (FFAs) directly into the cultured medium (Additional file 1: Figure S1, Additional file 2: Table S1) [17, 35, 37]. The first strategy, 'FFA Secretion' is based on a combination of three modifications: (1) weakening of polar cell wall layers by altering surface proteins and peptidoglycan layers, thereby allowing diffusion of FFA through phospholipid layers (deletion of sll1951 gene in SD232, SD277 and SD262); (2) preventing FFAs being channelled into competitive pathways (deletion of an acyl-ACP synthesis, slr1609 gene in all SD strains) and (3) overexpression of acyl-acyl carrier protein (ACP) thioesterases (TEs) thereby directing carbon flow into the production and secretion of FFAs. Shortening of fatty acids (C8-C14) was achieved via the expression of specific plant-based TEs, from Cinnamomum camphorum (14:0), Umbellularia californica (12:0) and Cuphea hookeriana (C8:0 and C10:0) [35, 40]. The second approach, the 'Green Recovery' technology, is based on enzymatic degradation of the lipids in photosynthetic membranes that is achieved by expression of lipolytic enzymes from Staphylococcus hyicus (shl, SD257, SD262), Fusarium oxysporum (fol, SD256, SD262) and $g p l$ from guinea-pig (SD262) under control of $\mathrm{CO}_{2}$-limitation-inducible promoter.

We have shown for the first time that Aspergillus fumigatus (A. fumigatus) cells can efficiently flocculate the unicellular cyanobacteria Synechocystis PCC 6803 and its genetically modified derivatives that have been designed for secretion of FFAs to the growth media where the hydrophobic droplets of secreted FFAs were used by fungal cells as the carbon source for growth and/ or for ex-novo production of lipids. The total lipid yields of the produced fungal-Synechocystis pellets were found to be higher than additive yields of lipids and intracellular/extracellular FFAs of the fungal and cyanobacterial components grown separately as mono-cultures. Synergistic effect of fungal-Synechocystis associations was 
also found in bioremediation rates when animal wastewater was used as an alternative source of nitrogen and phosphorus.

\section{Results}

\section{A. fumigatus growth on different carbon sources}

The cultures of filamentous fungi $A$. fumigatus produced dense spherical pellets, approximately $5-6 \mathrm{~mm}$ in size when grown on FGB containing $20 \mathrm{~g} / \mathrm{L}$ of glucose under $150 \mathrm{rpm}$ rotation (A. fumigatus/GLU) (Additional file 3: Figure S2). When grown on media without an extra carbon source $A$. fumigatus produced much smaller spherical pellets, approximately $1-2 \mathrm{~mm}$ in size (A. fumigatus) NEC). When grown on an alternative carbon source, $1 \%$ treated wheat straw (TWS), A. fumigatus produced pellets with diameters approximately $3-4 \mathrm{~mm}(A$. fumigatus/TWS).

A. fumigatus/NEC showed lowest growth rate; after 3 days growth yielding $1.3 \mathrm{~g} / \mathrm{L} \mathrm{DW}$ of biomass (Additional file 4: Figure S3). A. fumigatus/GLU showed the highest growth rate at $3.7 \mathrm{~g} / \mathrm{L} \mathrm{DW}$ and intermediate growth rate was recorded for $A$. fumigatus/TWS of $2.3 \mathrm{~g} / \mathrm{L}$ DW. Along with differences in growth rates, $A$. fumigatus grown on different carbon sources showed differences in lipid yields. Lipid yields were correlated with generated biomasses: $0.04 \mathrm{mg} / \mathrm{g} \mathrm{DW}, 0.08 \mathrm{mg} / \mathrm{g} \mathrm{DW}$ and $0.39 \mathrm{mg} / \mathrm{g}$ DW for A. fumigatus/NEC, $A$. fumigatus/TWS and $A$. fumigatus/GLU, respectively.

\section{Flocculation of Synechocystis cells by A. fumigatus}

Flocculation experiments were explained in Additional file 5: Figure S4. To assess flocculation efficiency $A$. fumigatus/GLU and A. fumigatus/TWS pellets were mixed with wild-type and genetically modified SD cultures that had been grown to cell densities of $1.0 \times 10^{9}$ cells $/ \mathrm{mL}$. Efficiency of harvesting was measured by the reduction in optical density and the numbers of uncaptured SD cells $24 \mathrm{~h}$ and $48 \mathrm{~h}$ after of co-cultivation with fungal pellets. Half maximal flocculation efficiencies $\left(\mathrm{FE}_{50}\right)$ were calculated as the minimum amount of $A$. fumigatus cells required to harvest $50 \%$ of the $1.0 \times 10^{9}$ cells/mL cells. A. fumigatus/GLU showed up to $86 \%$ flocculation when co-cultivated for $24 \mathrm{~h}$ with SD strains (Figs. 1, 2). This increased up to $97 \%$ after $48 \mathrm{~h}$ co-cultivation. Mixing A. fumigatus/TWS with SD strains showed up to $68 \%$ flocculation after $24 \mathrm{~h}$ followed by $80-90 \%$ of flocculation after 48 h. A. fumigatus/NEC showed 34-56 \% flocculation rates after $24 \mathrm{~h}$ of co-cultivation which increased to $60 \%$ after $48 \mathrm{~h}$. $\mathrm{FE}_{50}$ data for flocculation efficiencies is shown in Table 1.

To test toxicity of products produced during cultivation of A. fumigatus with $1 \%$ TWS we grew SD strains in the presence of 5 and $20 \%$ of the media collected $72 \mathrm{~h}$

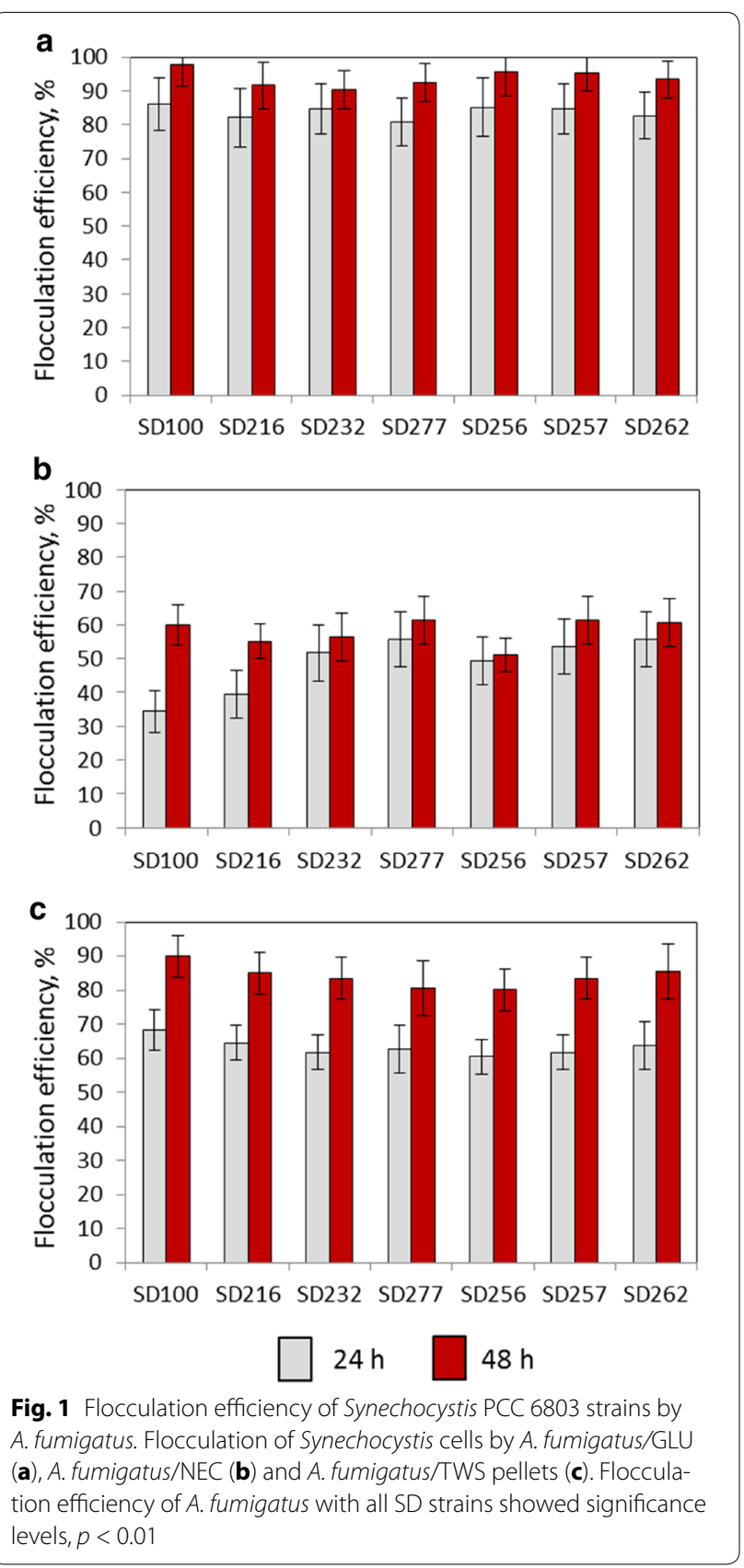

after incubation of $A$. fumigatus with $1 \%$ TWS (Additional file 6: Figure S5). No obvious effects were observed in presence of $5 \%$ TWS added to media. However, significant suppression of growth was observed in presence of $20 \%$ TWS. To avoid this effect $A$. fumigatus/TWS pellets were washed before mixing with SD cultures. This led to no suppression effect on SD strains growth (not shown).

Detailed light and environmental scanning electron microscopy of the A. fumigatus-SD pellets showed that cyanobacterial cells not only trapped within fungal 


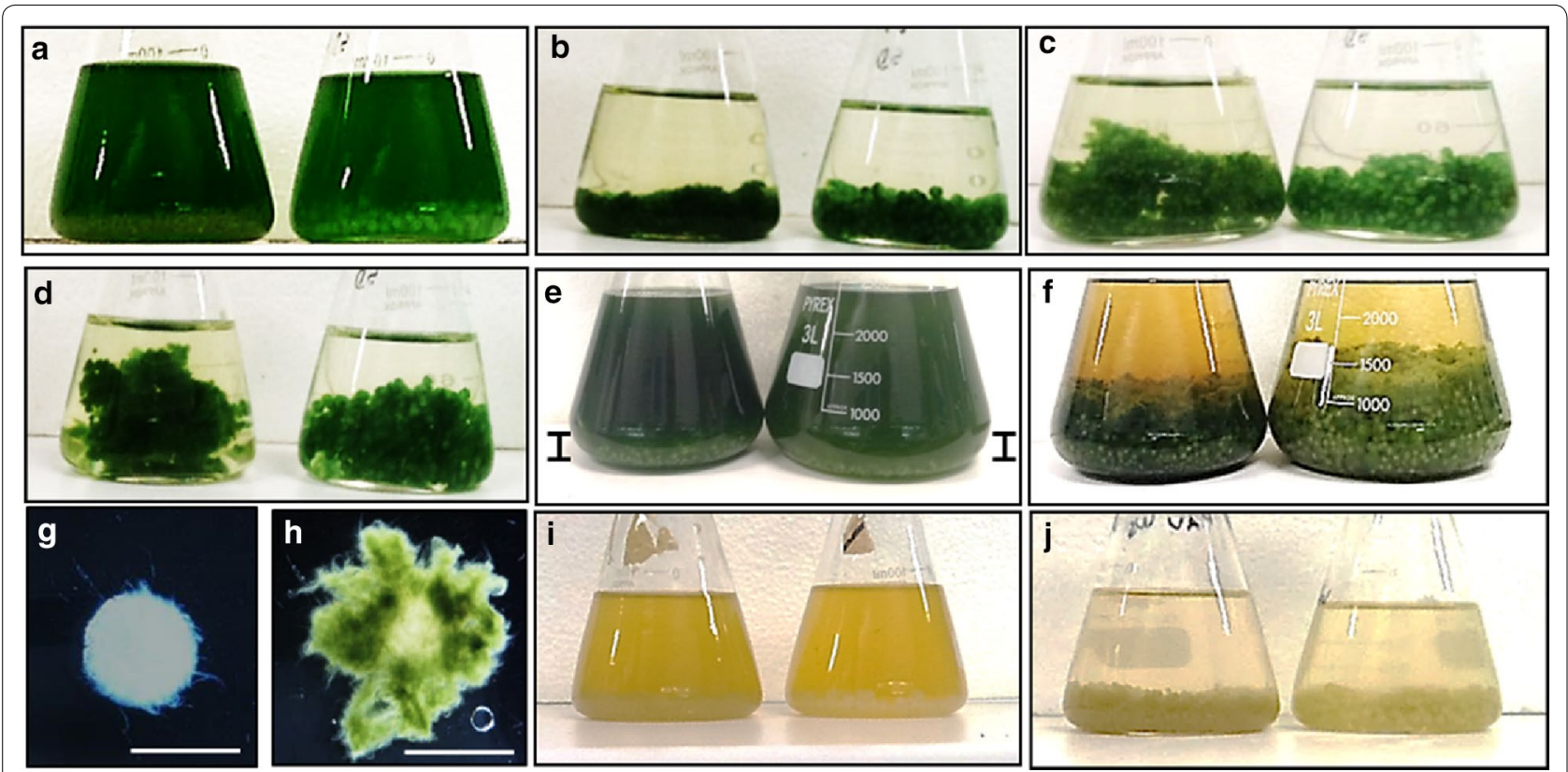

Fig. 2 Flocculation of Synechocystis PCC 6803 cells by A. fumigatus. a SD100 culture mixed with A. fumigatus/TWS and A. fumigatus/GLU pellets, time = 0; Flocculation of SD100 (b), SD216 (c) and SD232 (d) cells with A. fumigatus/TWS and A. fumigatus/GLU pellets $(t=24 \mathrm{~h}) ; \mathbf{e}$ Flocculation of SD277 with A. fumigatus/TWS and A. fumigatus/GLU pellets, $t=0$; vertical bars show the levels of A. fumigatus pellets in SD277 culture; f same after $24 \mathrm{~h} ; \mathbf{g}, \mathbf{h}$ A. fumigatus pellets before and after mixing with SD100 cells, respectively; i SD256 grown for 5 days under reduced $\mathrm{CO}_{2} \mathrm{Conditions}$ and mixed with A. fumigatus/TWS and A. fumigatus/GLU pellets, $t=0 ; \mathbf{j}$ same after $24 \mathrm{~h}$. In $\mathbf{a}-\mathbf{f}, \mathbf{i}-\mathbf{j}$ A. fumigatus/TWS pellets were shown on left and A. fumigatus/GLU on right. Scale $5 \mathrm{~mm}$

Table 1 Half maximal flocculation efficiency $\left(\mathrm{FE}_{50}\right)$ of SD strains by $A$. fumigatus

\begin{tabular}{|c|c|c|c|c|c|c|}
\hline \multirow[t]{2}{*}{ Species } & \multicolumn{2}{|c|}{ A. fumigatus/NEC } & \multicolumn{2}{|c|}{ A. fumigatus/GLU } & \multicolumn{2}{|c|}{ A. fumigatus/TSW } \\
\hline & FE50, gDW/I & $R^{2}$ & FE50, gDW/I & $R^{2}$ & FE50, gDW/I & $R^{2}$ \\
\hline SD100 & $6.01 \pm 1.5$ & 0.78 & $3.7 \pm 0.8$ & 0.85 & $5.8 \pm 1.1$ & 0.87 \\
\hline SD216 & $7.78 \pm 1.6$ & 0.81 & $3.9 \pm 0.9$ & 0.84 & $5.1 \pm 1.0$ & 0.81 \\
\hline SD232 & $7.2 \pm 1.7$ & 0.85 & $3.5 \pm 1.1$ & 0.78 & $4.0 \pm 1.0$ & 0.78 \\
\hline SD277 & $7.8 \pm 1.4$ & 0.84 & $3.8 \pm 0.9$ & 0.81 & $4.2 \pm 1.1$ & 0.85 \\
\hline SD256 & $7.78 \pm 1.6$ & 0.89 & $3.3 \pm 0.9$ & 0.84 & $5.1 \pm 1.0$ & 0.81 \\
\hline SD257 & $7.2 \pm 1.7$ & 0.85 & $3.5 \pm 1.1$ & 0.78 & $4.8 \pm 1.0$ & 0.78 \\
\hline SD262 & $6.8 \pm 1.4$ & 0.88 & $4.1 \pm 0.9$ & 0.81 & $4.2 \pm 1.1$ & 0.85 \\
\hline
\end{tabular}

filaments but were clearly attached to them (Fig. 3; Additional file 7: Figure S6).

\section{Zeta potential and cell size measurements}

The electrostatic charge distributions across the surfaces of the Synechocystis and A. fumigatus cells were evaluated by means of zeta potential values. Zeta potential values for Synechocystis cells grown in BG11 media showed strong negative surface charges between $-22.5 \mathrm{mV}$ (SD256) and $-33.1 \mathrm{mV}$ (SD100) (Table 2). The representatives of 'Green recovery' strains grown in $\mathrm{CO}_{2}$ enriched media showed slightly reduced negative surface charges, relative to wild type and 'FFA secretion' strains. A. fumigatus spores collected from the 3 week old plates showed strong negative zeta potential $(-48 \mathrm{mV})$. However, $A$. fumigatus submerged in BG11 after growing on different carbon sources showed positive zeta potential, $+2.6 \mathrm{mV}$ for $A$. fumigatus/GLU; $+0.9 \mathrm{mv}$ for $A$. fumigatus/TWS and $+1.2 \mathrm{mV}$ for $A$. fumigatus/NEC. To analyse whether A. fumigatus-assisted flocculation of Synechocystis cells is effect of neutralization or reduction of their negative surface charges we mixed SD100 and SD277 with A. fumigatus and analysed zeta potential values of pellets after flocculation. Extensive measurements of the electrostatic 

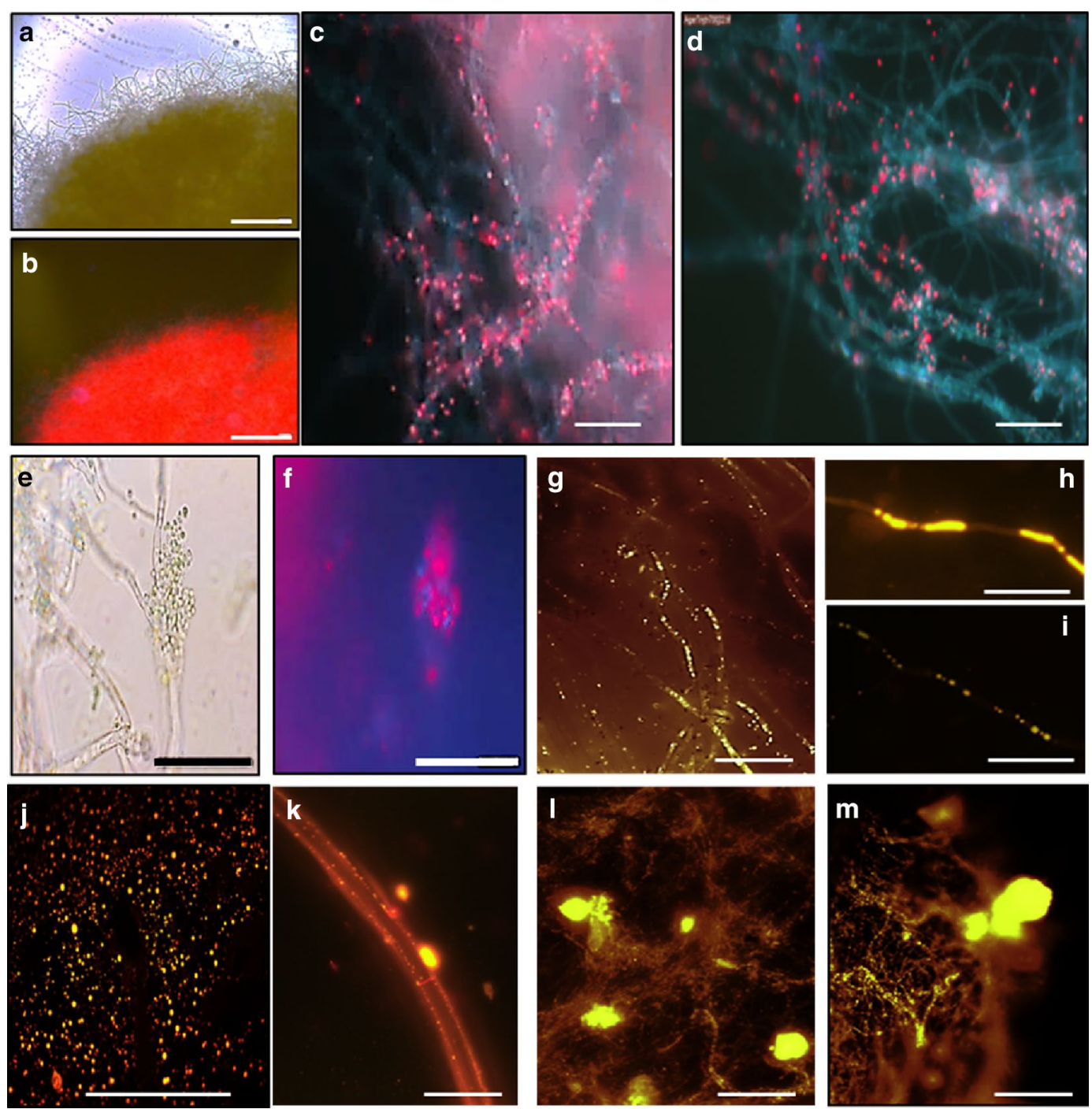

Fig. 3 Microscopic analysis of A. fumigatus-Synechocystis associations. a, b A. fumigatus-SD100 pellets; c, d A. fumigatus-SD100 and A. fumigatusSD216; e, f SD100 cells attached to A. fumigatus filaments; $\mathbf{g}, \mathbf{h}$ A. fumigatus/GLU filaments stained with Nile red; $\mathbf{i}$ A. fumigatus/TWS filaments stained with Nile red; $\mathbf{j}$ FFA droplets secreted into growth media by SD277 growing in mono-culture; $\mathbf{k}-\mathbf{m}$ FFA droplets attached to A. fumigatus filaments after mixing with SD232 (k) and SD277 (I, m) cultures at $t=0$. Red colour is the autofluorescence of cyanobacterial phycobilisomes. Scales $\mathbf{a}, \mathbf{b}=1 \mathrm{~mm} ; \mathbf{c}-\mathbf{m}=20 \mu \mathrm{m}$

charge distributions across the surfaces of the A. fumigatus-SD100 and $A$. fumigatus-SD277 pellets showed low negative values (from -2.5 to $-5.1 \mathrm{mV}$ ). Measurements of cell sizes showed that all genetically modified SD cells showed slightly larger sizes $(5.1-5.9 \mu \mathrm{M})$ than wild type SD100 cells $(3.6 \mu \mathrm{M})$ (Table 2).

\section{Biomass, lipid and FFA production in mono-cultured $A$. fumigatus and Synechocystis strains}

Before mixing with SD cultures mono-cultured A. fumigatus/GLU pellets had a lipid content of $11.1 \%(t=0$, Table 3). No secreted FFAs were detected in growth media. After an additional $24 \mathrm{~h}$ growth (control, $t=24 \mathrm{~h}$ ) the biomass of $A$. fumigatus pellets was slightly increased (from 1.0 to $1.77 \mathrm{gDW} / \mathrm{L}$ ). Not surprisingly, A. fumigatus/TWS pellets showed a lower lipid content, $3.4 \% \mathrm{DW}$ $(t=0$, Table 3). After a further $24 \mathrm{~h}$ of growth (control, $t=24$ ) biomass of $A$. fumigatus pellets increased to 1.5 gDW/L (4.2\% DW).

Prior to mixing with A. fumigatus pellets the Synechocystis PCC 6803 strains showed a wide range of lipid, intracellular and secreted FFA concentrations $(t=0$, Table 3). SD100 strain showed lowest concentrations of lipids/intracellular FFAs accounted up to $0.1 \%$ of DW 
Table 2 Zeta potentials and sizes of microalgal, Synechocystis and $A$. fumigatus cells

\begin{tabular}{|c|c|c|c|}
\hline Sample name & $\mathrm{ZP}, \mathrm{mV}$ & $\mathrm{pH}$ & Size, $\mathrm{nm}$ \\
\hline \multicolumn{4}{|l|}{ Algae and PCC 6803} \\
\hline C. vulgaris ${ }^{\mathrm{a}}$ & $-19.0 \pm 0.6$ & 6.8 & 4725.3 \\
\hline Isochrysis sp. ${ }^{a}$ & $-9.0 \pm 0.9$ & 6.5 & 15,540 \\
\hline $\mathrm{SD} 100^{\mathrm{a}}$ & $-33.1 \pm 2.9$ & 7.8 & 3567.6 \\
\hline $\mathrm{SD} 232^{\mathrm{a}}$ & $-30.1 \pm 2.6$ & 6.9 & 5974.3 \\
\hline $\mathrm{SD} 277^{\mathrm{a}}$ & $-31.2 \pm 1.8$ & 7.2 & 5177.5 \\
\hline $\mathrm{SD} 256^{\mathrm{a}}$ & $-22.5 \pm 2.0$ & 7.6 & 5513 \\
\hline $\mathrm{SD} 257^{\mathrm{a}}$ & $-25 \pm 1.9$ & 7.3 & 5087 \\
\hline \multicolumn{4}{|l|}{ A. fumigatus } \\
\hline A. fumigatus, spores ${ }^{b}$ & $-48.5 \pm 2.6$ & NA & NA \\
\hline A. fumigatus/FGBC & $-5.4 \pm 0.6$ & 7.3 & NA \\
\hline A. fumigatus/GLU ${ }^{d}$ & $2.6 \pm 0.6$ & 7.3 & NA \\
\hline A. fumigatus/TWS ${ }^{d}$ & $0.9 \pm 0.5$ & 7.7 & NA \\
\hline A. fumigatus/NEC ${ }^{d}$ & $1.2 \pm 0.9$ & 7.8 & NA \\
\hline \multicolumn{4}{|l|}{ A. fumigatus-SD } \\
\hline A. fumigatus/GLU-SD100 ${ }^{d}$ & $-2.5 \pm 0.8$ & 7.3 & NA \\
\hline A. fumigatus/TWS-SD100 ${ }^{d}$ & $-3.8 \pm 1.1$ & 7.5 & NA \\
\hline A. fumigatus/NEC-SD100 ${ }^{d}$ & $-4.8 \pm 1.9$ & 7.7 & NA \\
\hline A. fumigatus/GLU-SD277 ${ }^{d}$ & $-3.2 \pm 1.1$ & 7.3 & NA \\
\hline A. fumigatus/TWS-SD $277^{d}$ & $-4.4 \pm 1.5$ & 7.7 & NA \\
\hline A. fumigatus/NEC-SD277 ${ }^{d}$ & $-5.1 \pm 1.9$ & 7.8 & NA \\
\hline
\end{tabular}

a Zeta potential of cells grown in their growth media

${ }^{b}$ Zeta potential of A. fumigatus spores collected from 3 week old plates

c Zeta potential of cells grown in FGB media

d Zeta potential of cells grown in BG11

along with very low concentration of secreted FFAs, $0.41 \mathrm{mg} / \mathrm{L}(0.03 \% \mathrm{DW})$. After additional $24 \mathrm{~h}$ (control, $t=24 \mathrm{~h}$, Table 3 ) its biomass was increased up to $1.7 \mathrm{~g} / \mathrm{L}$ producing to $0.9 \mathrm{mg} / \mathrm{L}(0.03 \% \mathrm{DW})$ of secreted extracellular FFAs.

Constitutive expression of a bacterial TE gene (tesA) in Synechocystis strain SD216 led to increased levels of lipids, intracellular FFAs and secreted FFAs. At $t=0 \mathrm{~h}$ this strain accumulated lipids/internal FFAs at concentration of $2.4 \%$ DW, at a yield of $28.9 \mathrm{mg} / \mathrm{g}$ (Table 3). Concentration of secreted FFAs was $5.1 \%$ DW. After an additional $24 \mathrm{~h}$ biomass was increased up to $1.3 \mathrm{gDW} / \mathrm{L}$ producing $34.6 \mathrm{mg} / \mathrm{g}$ of lipids/intracellular FFAs (2.6 \%). Concentration of secreted FFAs was $61.9 \mathrm{mg} / \mathrm{L}$ representing $4.8 \%$ of DW (control, $t=24 \mathrm{~h}$ ).

Weakening of the cell walls in SD232 associated with the expression of two additional TEs, ChFatB2 and UcFatB1 led to a $33 \%$ increase in the concentrations of secreted FFAs compare to SD216 strain producing $94.3 \mathrm{mg} / \mathrm{L}$ of FFAs $(8.6 \%)$. However, concentration of lipids/intracellular FFAs was reduced up to $1.9 \%$ producing a yield of $21.8 \mathrm{mg} / \mathrm{g}$. The SD277 strain expressing codon-optimized tesA gene along with constitutive expression of three plant TEs; ChFatB2, CCFatB1 and UcFatB1, showed more than a 1.3-fold increase in secretion of FFA (12\% DW) compare to SD232. This was correlated with 2.2-fold decrease in intracellular lipid concentration $(0.88 \%)$. Growth for an additional $24 \mathrm{~h}$ resulted in an increase in biomass and in yield of lipids and both internal FFAs and secreted FFAs. This was observed in both SD232 and SD277 strains (control, $t=24 \mathrm{~h}$, Table 3).

For 'Green Recovery' experiments bubbling with $4 \%$ $\mathrm{CO}_{2}$ was stopped 3 days before mixing with fungal pellets (see "Methods" for details). At this stage strains SD256 and SD257 accumulated $39 \mathrm{mg} / \mathrm{g}(4.3 \%)$ and $42 \mathrm{mg} / \mathrm{g}$ (5.1\%) of lipids/intracellular FFAs, respectively. Amount of secreted FFAs from these cells was very low, $1.7 \mathrm{mg} / \mathrm{L}(0.2 \%)$ and $0.9 \mathrm{mg} / \mathrm{L}(0.1 \%)$, respectively (4 \% $\mathrm{CO}_{2}$, Table 4A). After 3 days growth under $\mathrm{CO}_{2}$ depleted conditions cultures started to decolorize, changing from blue/green to yellow as a result of degradation of photosynthetic membranes. At this time, $\left(\mathrm{CO}_{2}\right.$ limitation, $t=0 \mathrm{~h}$, Table 4B), the total biomass of cells (cell debris) was reduced, and in strains SD256 and SD257 concentrations of lipids/intracellular FFAs were just 2.7 and $2.9 \%$, respectively. This drop was associated with a 9.9-fold and a 21-fold increase in the concentrations of secreted FFAs from SD256 and SD257, respectively. The membrane damage, as a result of the expression of lipase genes in these strains led to FFA recoveries of 29 and $32 \%$ from cells of SD256 and SD257, respectively. Growing SD strains for a further $24 \mathrm{~h}$ did not change the lipid and FFA secretion profiles $\left(\mathrm{CO}_{2}\right.$ limitation, $t=24 \mathrm{~h}$, Table $\left.4 \mathrm{C}\right)$.

SD262 containing gene families involved in both technologies showed secretion of $26.9 \mathrm{mg} / \mathrm{l}$ of FFAs $(3.1 \%$ DW) before $\mathrm{CO}_{2}$ limitation as a results of 'FFA Secretion' machinery (Table 4A). Up-regulation of three lipase genes after 3 days of $\mathrm{CO}_{2}$ limitation has contributed to secretion of $48.3 \mathrm{mg} / \mathrm{l}(4.8 \% \mathrm{DW})$ of FFAs (Table 4B). Additional $24 \mathrm{~h}$ of growth did not affect FFA's secretion rates $\left(\mathrm{CO}_{2}\right.$ limitation, $t=24 \mathrm{~h}$, Table $\left.4 \mathrm{C}\right)$.

\section{Biomass, lipid and FFA production after co-cultivation of $A$. fumigatus/GLU with Synechocystis strains}

After $24 \mathrm{~h}$ of co-cultivation of A. fumigatus/GLU with SD100 the biomass of A. fumigatus/GLU-SD100 pellets was 1.4-fold higher than additive biomasses of both components grown in monocultures for $24 \mathrm{~h}$ (Table 3; Additional file 5: Figure S4, Additional file 8: Figure S7). This was correlated with increased production of lipids in these pellets: 1.3-fold higher than additive lipid, intracellular FFAs plus extracellular FFAs in both fungal and Synechocystis SD100 components grown in monocultures. 


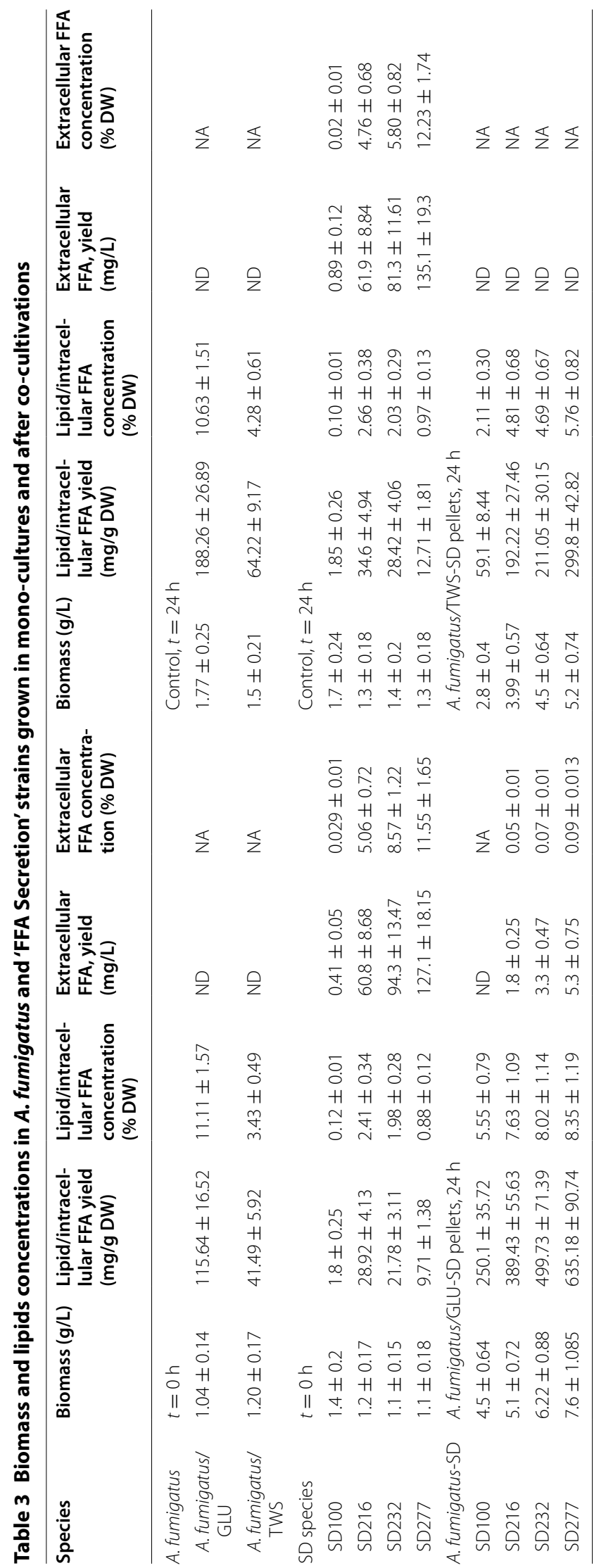


Table 4 Biomass and lipids concentrations in A. fumigatus and 'Green Recovery' strains grown in mono-cultures and cocultures

\begin{tabular}{|c|c|c|c|c|c|c|}
\hline Strains & Biomass (g/L) & $\begin{array}{l}\text { Lipid/intracellular } \\
\text { FFA yield } \\
\text { (mg/g DW) }\end{array}$ & $\begin{array}{l}\text { Lipid/intracellular FFA } \\
\text { concentration } \\
\text { (\% DW) }\end{array}$ & $\begin{array}{l}\text { Extracellular } \\
\text { FFA, yield } \\
\text { (mg/L) }\end{array}$ & $\begin{array}{l}\text { Extracellular FFA } \\
\text { concentration } \\
(\% \mathrm{DW})\end{array}$ & $\begin{array}{l}\text { FFA recovery } \\
\text { from lipids, } \%\end{array}$ \\
\hline \multicolumn{7}{|l|}{ SD strains } \\
\hline \multicolumn{7}{|c|}{ (A) $4 \% \mathrm{CO}_{2}$} \\
\hline SD256 & $0.89 \pm 0.12$ & $39 \pm 5.57$ & $4.38 \pm 0.62$ & $1.7 \pm 0.6$ & $0.19 \pm 0.1$ & NA \\
\hline SD257 & $0.82 \pm 0.10$ & $42 \pm 6.1$ & $5.12 \pm 09$ & $0.9 \pm 0.1$ & $0.11 \pm 0.2$ & NA \\
\hline SD262 & $0.87 \pm 0.12$ & $52 \pm 6.8$ & $5.97 \pm 0.89$ & $26.9 \pm 4.1$ & $3.09 \pm 0.44$ & NA \\
\hline \multicolumn{7}{|c|}{ (B) $\mathrm{CO}_{2}$ limitation $(t=0)$} \\
\hline SD256 & $0.65 \pm 0.15$ & $17.8 \pm 5.71$ & $2.73 \pm 0.51$ & $12.3 \pm 2.6$ & $1.89 \pm 0.1$ & $29.28 \pm 8.1$ \\
\hline SD257 & $0.71 \pm 0.17$ & $20.32 \pm 8.1$ & $2.86 \pm 0.91$ & $16.7 \pm 3.8$ & $2.35 \pm 0.4$ & $32.11 \pm 9.7$ \\
\hline SD262 & $1.0 \pm 0.2$ & $36.11 \pm 8.1$ & $3.61 \pm 0.71$ & $48.3 \pm 11.9$ & $4.83 \pm 1.3$ & NA \\
\hline \multicolumn{7}{|c|}{ (C) $\mathrm{CO}_{2}$ limitation (control, $t=24$ ) } \\
\hline SD256 & $0.60 \pm 0.11$ & $16.3 \pm 4.34$ & $2.61 \pm 0.74$ & $13.4 \pm 3.3$ & $2.24 \pm 0.3$ & $34.35 \pm 8.3$ \\
\hline SD257 & $0.70 \pm 0.15$ & $18.47 \pm 8.1$ & $2.86 \pm 0.91$ & $18.0 \pm 4.9$ & $2.57 \pm 1.5$ & $33.85 \pm 12.1$ \\
\hline SD262 & $1.1 \pm 0.6$ & $30.46 \pm 11.1$ & $2.7 \pm 0.47$ & $52.3 \pm 12.9$ & $4.75 \pm 1.2$ & NA \\
\hline \multicolumn{7}{|c|}{ A. fumigatus/GLU-SD } \\
\hline \multicolumn{7}{|c|}{ (D) Co-cultivation of A. fumigatus/GLU with SD strains ( $t=24 \mathrm{~h}$ ) } \\
\hline SD256 & $3.9 \pm 0.6$ & $280 \pm 41.1$ & $7.17 \pm 1.1$ & ND & NA & NA \\
\hline SD257 & $4.1 \pm 0.5$ & $302 \pm 38.9$ & $7.36 \pm 1.1$ & ND & NA & NA \\
\hline SD262 & $5.8 \pm 1.7$ & $468.35 \pm 68.8$ & $8.08 \pm 1.2$ & ND & NA & NA \\
\hline \multicolumn{7}{|c|}{ A. fumigatus/TWS-SD } \\
\hline \multicolumn{7}{|c|}{ (E) Co-cultivation of A. fumigatus/TWS with SD strains ( $t=24 \mathrm{~h}$ ) } \\
\hline SD256 & $3.29 \pm 0.4$ & $112.22 \pm 16.1$ & $3.81 \pm 0.5$ & ND & NA & NA \\
\hline SD257 & $3.5 \pm 0.6$ & $140.05 \pm 25.1$ & $4.00 \pm 0.7$ & ND & NA & NA \\
\hline SD262 & $4.6 \pm 0.5$ & $239.8 \pm 53.9$ & $5.21 \pm 0.4$ & ND & NA & NA \\
\hline
\end{tabular}

With consideration of the observed 81-86\% efficiency of flocculation of Synechocystis cells the total biomasses A. fumigatus/GLU-SD216, A. fumigatusGLU-SD232 and A. fumigatus/GLU-SD277 pellets were increased 1.8-, 2.1- and 2.7-fold, respectively compare to the total (additive) biomass of pairs of components grown in monocultures (Table 3; Additional file 8: Figure S7). This was correlated with increases in yield of lipid/intracellular FFAs which were accounted up to 1.4-, 1.7- and 1.9-fold higher than the additive yields of lipid/intracellular FFAs and extracellular FFAs of mono-cultured A. fumigatus and SD216, SD232 and SD277 strains, respectively. FFAs droplets which were clearly seen in growth media and were attached to the fungal filaments immediately after mixing (Fig. 3) were not detected after $24 \mathrm{~h}$ of co-cultivation (data not shown).

Flocculation of strains SD256 and SD257 strains grown under $\mathrm{CO}_{2}$ limited conditions with $A$. fumigatus is shown in Fig. 2 and Additional file 9: Figure S8. Again, with consideration of the observed 83-85\% efficiency of flocculation total biomasses $A$. fumigatus/GLU-SD256, $A$. fumigatus-SD257 and $A$. fumigatus-SD262 pellets were increased 1.6-, 1.7- and 12-fold, respectively, over monoculture additive biomasses (Table 4D; Additional file 8: Figure S7). This was correlated with 1.1-, 1.2- and 1.5-fold increases in yields of lipid/intracellular FFAs in SD256, SD257, SD262 pellets, respectively, compare to the additive yields of lipid/intracellular FFA and extracellular FFA extracted from mono-cultured A. fumigatus and the Synechocystis strains.

\section{Biomass, lipid and FFAs production after co-cultivation of $A$. fumigatus/TWS with Synechocystis strains}

Total biomasses and extracted lipids/internal FFAs from A. fumigatus/TWS-co-cultivated with Synechocystis strains SD216, SD232 and SD277 pellets were all also higher than the additive biomasses and yields of lipids/ intracellular FFAs of the fungal and cyanobacterial components grown in monocultures. With consideration of 61-68\% efficiency of flocculation after $24 \mathrm{~h}$ total biomasses A. fumigatus/TWS- SD216, A. fumigatus/ TWS-SD232 and $A$. fumigatus/TWS-SD277 pellets were increased 1.5-, 1.6- and 2.1-fold, respectively. This correlated with 1.1-, 1.1- and 1.3-fold increases in the yields of 
extracted lipids/internal FFAs compare to additive yields of lipids/internal FFAs and secreted FFAs of the components grown $24 \mathrm{~h}$ as monocultures (Table 3; Additional file 8: Figure S7).

For 'Green Recovery' strains total biomasses and yields of extracted lipids/internal FFA from $A$. fumigatus/TWSSD256, A. fumigatus/TWS-SD257 and A. fumigatus/ TWS-SD262 pellets were also all higher than additive biomasses and lipids/FFAs yields of the fungal and cyanobacterial components grown in mono-cultures (Table 4E; Additional file 8: Figure S7). Again, taking into consideration the observed 61-68\% efficiency of flocculation after first $24 \mathrm{~h}$ total biomasses of pellets were increased 1.4-, 1.6- and 1.9-fold, respectively. This was correlated with respective 1.0-, 1.2- and 1.4-fold increase in the yields of extracted lipids/internal FFA compare to additive yields of lipids/internal FFA and secreted FFA of the components grown $24 \mathrm{~h}$ in monoculture.

\section{Fatty acids composition in A. fumigatus-SD pellets}

Fatty acid composition (measured as fatty acids methyl esters, FAMEs) of A. fumigatus/GLU and A. fumigatus/ TWS pellets, Synechocystis species and pellets of fumigatus/TWS-Synechocystis strains are shown in Fig. 4. Fatty acid composition of $A$. fumigatus/GLU was dominated by oleate, C18:1 (ca $30 \%$ ) linoleate, C18:2 (ca $30 \%$ ), and palmitate, C16:0 (ca $20 \%$ ) [23, 27, 28]. A. fumigatus/TWS pellets showed similar proportions of these fatty acids.

Intracellular lipid and FFA's composition of Synechocystis SD100 strain was also dominated by palmitate, C16:0 (49\%) [24]. Unlike A. fumigatus cells, the Synechocystis SD100 showed high proportions of stearate, C18:0 (18 \%)
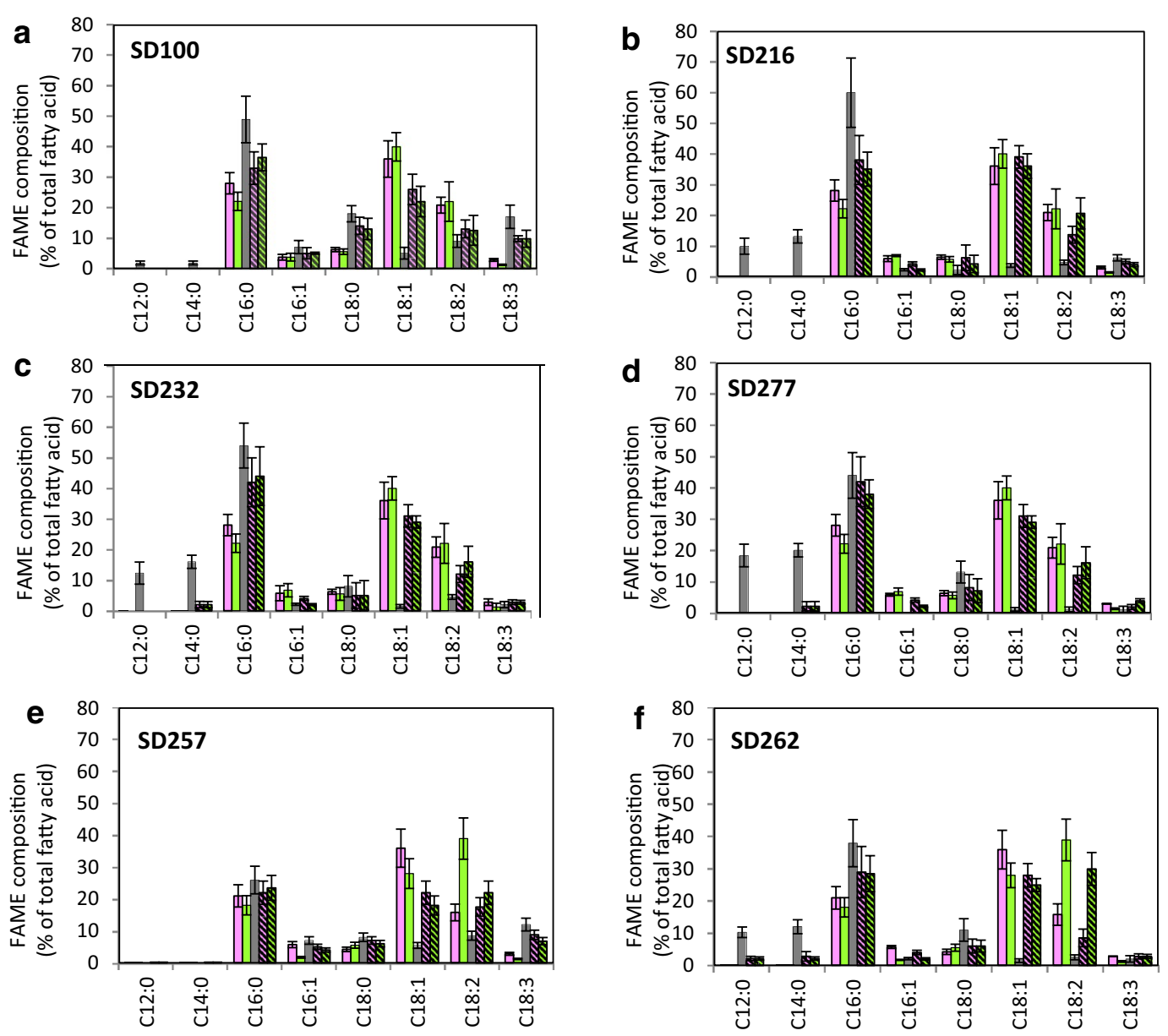

\section{$1 \square 2 \square 3 \mathbb{N} 5$}

Fig. 4 Fatty acids composition of lipids in A. fumigatus, SD strains and A. fumigatus-SD pellets. 1 A. fumigatus/TWS; 2 A. fumigatus/GLU; 3 SD strains; 4 A. fumigatus/TWS-SD pellets; 5 A. fumigatus/GLU-SD pellets 
and linolenate, 18:3 (10\%). Very low concentrations of short fatty acids were observed in the SD100 strains, with only $2 \%$ of both, lauric acid (C12:0) and myristic acid (C14:0).

The 'FFA Secretion' strains, SD216, SD232 and SD277 all showed increased levels of short fatty acids, C12:0 and C14:0 relative to the SD100 strain with the concentration of C12:0 increased 5.4-, 6.8- and 10-fold, respectively. The levels of C14:0 were also increased 7.2-, 8.8- and 11-fold, respectively. This increase was associated with decreases in levels of longer chain fatty acids, C18:0, C18:1, C18:2 and C18:3. The 'Green Recovery' strains, SD256 and SD257 had fatty acid compositions that resembled wild type SD100 showing elevated concentrations of unsaturated fatty acids, C18:1, C18:2 and C18:3. SD262 showed fatty acid composition of both SD100 and SD232 strains accumulating both unsaturated and short-chain fatty acids.

Fatty acid compositions of the A. fumigatus-Synechocystis pellets are also shown in Fig. 4 . In all cases, both $A$. fumigatus and SD strains co-contributed to the level of palmitate (C16:0). A. fumigatus was a main contributor of the oleate, (C18:1) and linoleate (C18:2). Synechocystis SD100 and SD257 were the main contributors of the linolenate (C18:3).

Composition of extracellular FFAs secreted from genetically modified Synechocystis SD strains resembled their intracellular lipid and FFAs composition, showing high levels of C16:0 and C18:0, along with short-chain fatty acids (Fig. 5). Composition of FFAs that accumulated in media containing A. fumigatus-SD216, A. fumigatus -SD232 and $A$. fumigatus-SD277 pellets was mainly C18:0 and was enriched in short fatty acids, C:12 and C14:0 with practically no detectable longer FFAs (longer than C:18). Composition of FFAs secreted from Synechocystis SD257 and SD262 strains was similar to composition of FFA secreted from the Synechocystis SD100 and SD232 strains.

\section{Swine wastewater as an alternative source of nutrients for A. fumigatus-SD100 pellets}

We assessed the ability of A. fumigatus-SD100 pellets for growth and absorption the nitrogen and phosphorus $\left(\mathrm{NH}_{4}^{+}\right.$and $\left.\mathrm{PO}_{4}^{-3}\right)$ from swine wastewater (SWW) (Table 5; Additional file 10: Figure S9). For these experiments, the swine wastewater was diluted to either 10 or $25 \%$ with tap water. After 48 h of growth of A. fumigatusSD100 pellets in $25 \%$ wastewater the concentration of $\mathrm{NH}_{4}{ }^{+}-\mathrm{N}$ reduced from 164.3 to $18.2 \mathrm{mg} / \mathrm{L} \mathrm{(89 \% )} \mathrm{and} \mathrm{the}$ concentration of $\mathrm{PO}_{4}^{-3}-\mathrm{P}$ reduced from 38.7 to $9.8 \mathrm{mg} / \mathrm{L}$ (75\%). This removal efficiency was higher than achieved separately by Synechocystis SD100 (30\% for $\mathrm{NH}_{4}{ }^{+}-\mathrm{N}$ and $26 \%$ for $\mathrm{PO}_{4}^{-3}-\mathrm{P}$ ) and by $A$. fumigatus (52 and $45 \%$, for

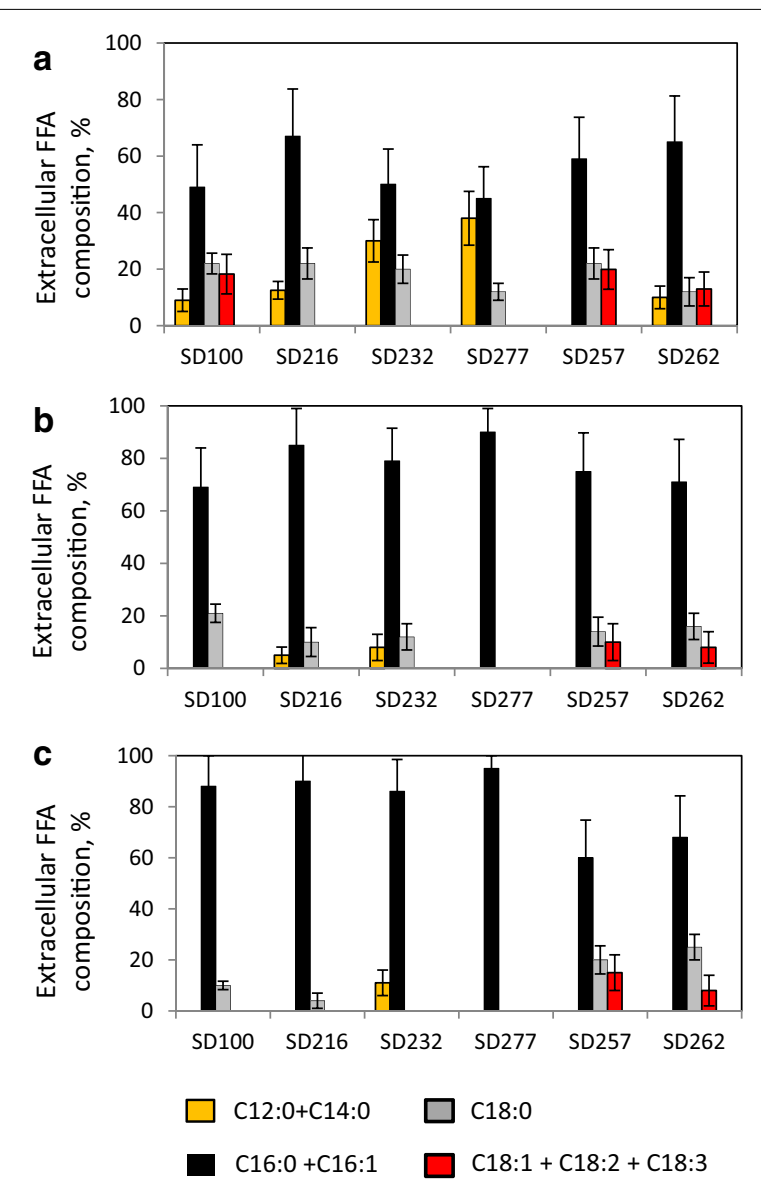

Fig. 5 Composition of FFA secreted from A. fumigatus, SD strains and A. fumigatus-SD pellets. a SD strains; b A. fumigatus/TWS-SD pellets; c A. fumigatus/GLU-SD pellets

$\mathrm{NH}_{4}{ }^{+}-\mathrm{N}$ and $\mathrm{PO}_{4}^{-3}-\mathrm{P}$ respectively). In $10 \% \mathrm{SWW}$ both nutrients were almost completely removed after $48 \mathrm{~h}$ incubation with $A$. fumigatus-SD100 alone (98\% removal for $\mathrm{NH}_{4}^{+}-\mathrm{N}$ and $84 \%$ removal of $\left.\mathrm{PO}_{4}^{-3}-\mathrm{P}\right)$. Nutrient uptake by $A$. fumigatus-SD100 pellets led to 2.3 -fold increase in their biomass production after $48 \mathrm{~h}$ of treatment and this correlated with a 1.5-fold increase in lipid yield (Fig. 6).

\section{Discussion}

Biomass and lipid production in A. fumigatus-Synechocystis associations

In this study we used the model cyanobacterium, Synechocystis sp. PCC6803 and derivative strains that have been genetically modified either for secretion of FFAs or for recovery of FFAs from photosynthetic lipids [17, 35]. Accumulation of FFA droplets in growth media by these strains was up to $12 \%$ DW for the 'FFA Secretion' and $3.6 \%$ DW for the 'Green Recovery' genetically modified strains. Whilst the “Green Recovery' strains displayed 
Table 5 Concentrations of nutrients in $25 \%$ swine wastewater before and after treatment with A. fumigatus, SD100 and $A$. fumigatus-SD100 pellets

\begin{tabular}{|c|c|c|c|c|c|c|c|c|}
\hline \multicolumn{3}{|l|}{ ASW } & \multicolumn{2}{|l|}{ A. fumigatus } & \multicolumn{2}{|l|}{ SD100 } & \multicolumn{2}{|c|}{ A. fumigatus-SD100 } \\
\hline Concentrations & NH4-N, mg/L & PO4-P, mg/L & NH4-N, mg/L & PO4-P, mg/L & NH4-N, mg/L & PO4-P, mg/L & NH4-N, mg/L & PO4-P, mg/L \\
\hline ASW, $100 \%$ & $680.7 \pm 23.1$ & $145.4 \pm 13.7$ & NA & NA & NA & NA & NA & NA \\
\hline ASW, $25 \%$ & $164.3 \pm 13.2$ & $38.7 \pm 3.4$ & $78.8 \pm 8.2$ & $21.2 \pm 3.6$ & $114.2 \pm 12.1$ & $28.5 \pm 5.3$ & $18.2 \pm 6.1$ & $9.8 \pm 3.0$ \\
\hline ASW $10 \%$ & $66.1 \pm 4.3$ & $16.1 \pm 3.0$ & $25.2 \pm 2.8$ & $8.0 \pm 2.9$ & $44.3 \pm 4.2$ & $11.9 \pm 2.2$ & $1.1 \pm 0.9$ & $2.5 \pm 0.8$ \\
\hline
\end{tabular}

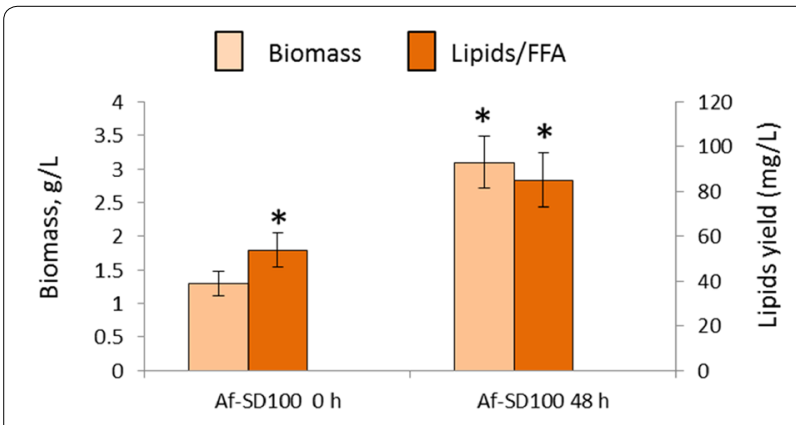

Fig. 6 Biomass and lipid production in A. fumigatus-SD100 pellets grown in $25 \%$ swine wastewater. Af-SD100: A. fumigatus-SD100 pellets. Significance levels: ${ }^{*} p<0.05$

lower levels of secreted FFAs, these were however up to 103-fold higher than FFAs secretion levels for the wildtype, Synechocystis sp. PCC6803 SD100 strain.

In spite of the obvious attractiveness of both metabolic reprogramming strategies the extraction with organic solvents of secreted FFAs from large amounts of water with organic solvents will be challenging and may not be economically viable. Apart from secreted FFAs, substantial biomass of cyanobacterial cells (or their debris) produced in both systems also contributes to total yields of bio-oil production [17, 35]. However, harvesting of cyanobacterias cells for a cost-effective large scale biofuel production will face the same challenges as those faced by the microalgal industry.

Our recent study showed that $A$. fumigatus can efficiently flocculate a large number of microalgal species, including seawater and freshwater species [27, 28]. Representatives of other Aspergillus species also showed high flocculation rates with freshwater microalgae $C$. vulgaris [23-26, 29, 41]. Fungal-assisted flocculation of marine microalgae, Nannochloropsis sp was described by [30].

In this research it was shown that $A$. fumigatus can harvest up to 80-86 \% of Synechocystis cells after the first $24 \mathrm{~h}$ co-cultivation and almost $100 \%$ after $48 \mathrm{~h}$ with $\mathrm{FE}_{50}$ around $3.6 \mathrm{gDW} / \mathrm{L}$. Interestingly, in the fungalSD pellets the Synechocystis cells were shown not only to be entrapped within the scaffolds of fungal filaments but clearly attached to them (Fig. 3). Similar types of fungal-algal interactions were described in our previous papers $[27,28]$. Although the detailed mechanism of this type of fungal-algal interaction is unclear, the interaction between oppositely charged surfaces may enable microalgal attachment to the fungal cell wall. The microalgae possess a negative surface charge due to the presence of proton-active carboxylic, phosphoric, phosphodiester, hydroxyl and amine functional groups. The zeta potential of microalgae was found to be within the range from -10 to $-35 \mathrm{mV}$ [42]. Using coagulating agents it was shown that reduction of the magnitude of the zeta potential to approximately $-10 \mathrm{mV}$ and below is required for removal of four algae species A. formosa, Melosira sp., M. aeruginosa, and $C$. vulgaris [42].

We found that the electrostatic charge distribution across the surface of the cells of $A$. fumigatus cells depend on the age of the conidia/spores and $\mathrm{pH}$. Spores collected from the agar plates showed strong negatice surface charge $(-48.5 \mathrm{mV})$. Being submerged in BG11 surface charges of $A$. fumigatus were positive $(+0.9$ to $+2.6 \mathrm{mV}$ ). Similar results were shown for $B$. bassiana where zeta potential for aerial conidia varied from +22 to $-30 \mathrm{mV}$ when $\mathrm{pH}$ values were ranging from 3 to 9 [43]. For submerged conidia the net surface charge was ranged from +10 to $-13 \mathrm{mV}$. And much less variation observed for spores, +4 to $-4 \mathrm{mV}$. The charge difference between Aspergillus flavus $(+46.1 \mathrm{mV})$ and microalgae cells $(-23.7 \mathrm{mV})$ was suggested to be essential for their flocculating interaction [41]. In our experiments Synechocystis cells showed strong negative surface charges.

Differences in surface charges between SD cells and fungal cells in BG11 supplemented with different carbon sources did not always correlated with their flocculation rates and FE50 values. A. fumigatus/GLU cells showed more positive zeta potential $(+2.6 \mathrm{mV})$ than $A$. fumigatus/TWS $(+0.9 \mathrm{mv})$ which correlates with differences in their flocculation rates and FE50 values. However, $A$. fumigatus/NEC showed more positive zeta potential $(+1.2 \mathrm{mV})$ that $A$. fumigatus/TWS which does not correlates well with its lower flocculation efficiency and higher FE50 value. However, neutralization rates as a result of interactions between strongly negative surface potentials 
of SD cells and positive surface charges $A$. fumigatus cells growing on different carbon sources correlated with their flocculation efficiencies and FE50 values. Zeta potential of the A. fumigatus/GLU-SD100 pellets is less negative, $(-2.5 \mathrm{mV})$ than the zeta potential of the A. fumigatus/ NEC-SD100 $(-4.8 \mathrm{mV})$. Zeta potential of the A. fumigatus/TWS-SD100 showed intermediate value $(-3.8 \mathrm{mv})$. Similar results were obtained for the A. fumigatus-SD277 pellets. It is not clear whether this charge difference is enough to keep Synechocystis cells strongly attached to filaments. Our previous research showed that A. fumigatus can also efficiently trap highly motile microalgal strains such as $C$. reinhardtii and T. chuii $[27,28]$. This is difficult to explain only by differences in their surface charges. Moreover, observation that microalgal and Synechocystis cells not only attach to A. fumigatus fungal filaments, but also to each other suggests that produced cell wall-free protoplasts have lost their negative charges. Production of protoplasts was previously shown to be triggered by secretion of cellulases by fungal cells $[27,28]$. Fungal cells can secrete a cocktail of concentrated exopolysaccharide molecules during interaction with other microrganisms $[28,44,45]$. This suggests that as an alternative or an additional scenario Synechocystis cells can be entrapped by cocktails of 'sticky' exopolysaccharides secreted by $A$. fumigatus. Metabolomic analysis of media after co-cultivation of A. fumigatus with Synechocystis with microalgal strains could reveal more information about the biochemistry of fungal-assisted flocculation.

The lipid and FFA yields and their respective compositions in fungal-Synechocystis sp. PCC6803 pellets showed complex profiles. This complexity may be a reflection of at least two factors: (1) lipid and FFA concentrations in fungal and Synechocystis cells prior to and during co-cultivation and (2) the efficiencies of Synechocystis cell flocculation by $A$. fumigatus [23-27, 29, 46].

Fatty acid composition of all fungal-SD pellets obviously reflected the compositions of both fungal and Synechocystis components. Similar results were described for a number of fungal-assisted microalgal flocculation [2329]. Being a major contributor of lipids in A. fumigatusSD pellets, fungal cells were also the main contributor of medium-length fatty acids, oleates, C18:1 and linoleates, C18:2. In all instances, both A. fumigatus and Synechocystis strains contributed to the level of palmitates (C16:0), and SD232, SD277 and SD262 strains were solo contributors of short-length fatty acids, C12:0 and C14:0. The composition of saturated, extracellular FFAs secreted from genetically modified Synechocystis strains resembled their compositions in lipids and intracellular FFAs: they were enriched by C18:0 together with low levels of short fatty acids. Interestingly, unsaturated fatty acids palmitoleates (C16:1), oleates, $(\mathrm{C} 18: 1)$, linoleates, $(\mathrm{C} 18: 2)$ and linolenates, (18:3) were missing in A. fumigatus pellets in "FFA secretion" strains.

\section{De novo lipid production in A. fumigatus-Synechocystis associations}

Most microorganisms including fungi have robust machinery for the assimilation of sugars channelling them into lipid biosynthesis ("de novo" lipid accumulation) or diverting them into different carbohydrates which can promote their growth [47-59]. Starch and cellulose are the most abundant carbohydrates accumulated in microalgae and cyanobacteria cells [60, 61]. Starch accumulates in cytoplasm and chloroplasts. Cellulose accumulates mainly in cell walls representing a primary target when an additional carbon source is required in symbiotic associations of algae/cyanobacteria with other organisms [14]. In lichens, natural fungal-algal symbiotic associations, the fungal component can secrete hydrolytic enzymes to utilise microalgal cells walls during winter time when production of secreted carbohydrates from algae is limited because of suppressed photosynthesis [62]. Only a few cyanobacterial exopolysaccharides have been defined structurally, although some details of their composition are known $[63,64]$. The sheaths of some of them contain celluloselike homoglucan fibrils which are cross-linked by minor monosaccharides. The enzymatic cellulose degradation requires three types of enzymes: (1) endoglucanases, which break bonds in the crystalline structure of cellulose; (2) exoglucanases, which hydrolyse cellulose-forming free sugars or cellobiose; and (3) cellobiases, which hydrolyse intermediates generated by the action of these enzymes to free sugars [14]. Fungal cells can secrete a cocktail of hydrolytic enzymes containing cellulases along with hemicellulases, laccases and manganese peroxidase that in turn can convert cell wall polymers into reduced sugars that can then be utilized as a carbon source [65-71]. Production of microalgal cell wall-free protoplasts after co-cultivation of microalgal cells with A. fumigatus was recently shown $[27,46]$, and a correlation between enhanced biomass of the fungal-algal pellets and secretion of cell-wall degrading cellulases was also observed after co-cultivation of the different filamentous fungal strains with $C$. vulgaris $[23-26,29]$. In our experiments $A$. fumigatus-SD100 pellets showed 1.4fold increases in biomass compare to additive biomasses of the both components when grown as monoculture (Table 3). This was correlated with 1.3-fold increase in production of total lipids. This suggests that A. fumigatus may potentially utilize the cell wall carbohydrates or carbohydrates secreted from Synechocystis cells as a carbon source. 


\section{Ex novo lipid production in A. fumigatus-Synechocystis associations}

Some microorganisms can also use fatty acids and hydrophobic polymers, such as vegetable oils, industrial fats or fish oils as carbon sources. This process is called "ex novo lipid accumulation" [72-77]. Ex novo accumulation is often accompanied by the secretion of lipases that catalyse hydrolysis of hydrophobic polymers into FFA, which can then be transported into the cells using active transport mechanisms. If, however, the concentration of FFAs is high they can diffuse freely into the microbial cells $[78,79]$. Absorbed FFAs can be converted and stored as TAGs and steryl esters incorporated into lipid bodies. Alternatively, FFAs can be directly used for cell growth and proliferation [80-83]. In the latter scenario FFAs can be converted into acyl-CoA esters by acyl-CoA synthetases followed by their degradation into smaller chain acyl-CoA ester and acetyl-CoA by the $\beta$-oxidation process, catalysed by various acyl-CoA oxidases providing the energy necessary for cell growth, maintenance and the production of intermediate metabolites [84]. Effects of exogenous FFAs on different microorganism's growth were shown to vary extensively. Depending on their concentrations, composition and growth conditions (light/ dark, aerobic/anaerobic), FFAs could inhibit or work as growth stimulating factors for different microorganisms [85-87].

The representatives of 'FFA Secretion' and 'Green Recovery' strains were observed to secrete substantial amounts of FFAs into the growth media. However, Nile Red staining and FFA extraction revealed no detectable FFAs in media after co-cultivation with A. fumigatus. There appeared to be a direct link between levels of secreted FFAs that accumulated in media before co-cultivation and total biomass and lipid yields in A. fumigatusSynechocystis pellets. Total biomass and yields of lipids and intracellular FFAs that accumulated in A. fumigatusSynechocystis pellets were higher than the additive yields of lipids and intracellular FFAs plus the extracellular FFAs that accumulated in cells and growth media prior to co-cultivation [83]. A. fumigatus-Synechocystis SD277 pellets showed a 2.7 -fold increase in total biomass and 1.9-fold increase in accumulation of lipids and internal FFAs. It is unclear whether observed increases are only due to ex novo biosynthesis or other molecules including secreted carbohydrates or Synechocystis cell wall components be potentially used by fungal cells for growth and lipid production. This was indicated, however, that ex novo biosynthesis of lipid material cannot take place at the same time as the de novo process since FFAs can inhibit two key genes involved in de novo lipid accumulation: ATP-citrate lyase and fatty acid synthetases [88-90].

\section{Alternative carbon, nitrogen and phosphorus sources for growing A. fumigatus-Synechocystis associations}

Application of alternative carbon sources from lignocellulosic waste for large scale fungal and algal biomass production has been explored extensively. Our recent studies have shown that $A$. fumigatus grown on $1 \%$ TWS as the sole carbon source showed increasing growth rate compared to A. fumigatus grown on carbon-free media (Additional file 3: Figure S2, Additional file 4: Figure S3) [26-28]. A. fumigatus, however produced more biomass and higher lipid yields when grown on glucose. A. fumigatus/TWS cells showed efficient trapping of the microalgal and cyanobacterial strains within the first $48 \mathrm{~h}$. There may be more than one reason why A. fumigatus/TWS-Synechocystis pellets showed lower values of total biomass and lipid production compare to A. fumigatus/GLU-Synechocystis pellets. These reasons include: (1) lower flocculation efficiency of $A$. fumigatus/TWS pellets; (2) lower lipid and FFA concentrations in A. fumigatus/TWS before and during co-cultivation and (3) potential negative effect of de novo on ex novo lipid production inhibited by reduced sugars and low molecular weight products of TWS's digestion. The application of wheat straw biomass for fungal-assisted flocculation needs to be further optimised to improve their flocculation efficiency and reduce production of potentially toxic chemicals. This strategy offers a greater potential to improve the economics of fungal-cyanobacterial biotechnology for biofuel production.

For decades mono-cultured algal/cyanobacterial and fungal cells have been used extensively for recovery of $\mathrm{N}$ and $\mathrm{P}$ and microelements from a variety of wastewaters [91-99]. Efficient wastewater treatment by A. fumigatus/ microalgal systems has previously been shown [26, 27, 41, 46]. Genetically modified Synechocystis sp. PCC 6803 expressing a novel lactate dehydrogenase gene involved in D-lactate biosynthesis a feedstock for food, pharmaceutical and plastic industries was growing on BG11 supplemented with alternative sources on $\mathrm{N}$ and $\mathrm{P}$ from wastewater from municipal sludge subjected to anaerobic digestion [100]. Obtained results showed that wastewater nutrients can enhance D-lactate synthesis by $40 \%$ improving economics of this technology. In this present study it was shown that the co-cultivation of $A$. fumigatus-Synechocystis pellets produced a synergistic effect on absorption of ammonium and phosphates from diluted SWW. This synergistic effect of fungi and microalgae on nutrient removal from wastewater has great potential to be applied to pilot-scale wastewater-based wastewater system cultivated in continuous or semi-continuous mode. 


\section{Conclusions}

Metabolic engineering provides tools for the reprogramming of biochemical pathways and offers opportunities for generating organisms with tailored composition of essential molecules that can in turn be used directly as petrochemicals or can be converted into aviation and transportation fuels. The fungal-assisted harvesting of unicellular cyanobacteria Synechocystis PCC 6803 and its genetically modified derivatives described in this study may help resolving a number of challenges which large scale algal/cyanobacterial biotechnology is facing:

1. Efficient harvesting of Synechocystis cells. A. fumigatus cells can harvest up to $100 \%$ of Synechocystis SD strains after $48 \mathrm{~h}$ of co-cultivation.

2. Enhancement of total biomass, lipid production and optimization of fatty acids composition. Fungal-Synechocystis pelletization showed synergetistic effects on total biomass and lipid production. The composition of FFAs in these associations can be tailored through co-cultivating of fungal cells with different cyanobacterial species.

3. Carbon, nitrogen and phosphorus from waste stream biomass as an alternative, sustainable and renewable nutrient supply. Use of alternative $\mathrm{C}, \mathrm{N}$ and $\mathrm{P}$ sources from agricultural waste and wastewaters may potentially improve the economics of large scale biofuel production using cyanobacterial cells.

4. Application of ex novo lipid biosynthesis for biofuel production. Conventional, de novo production of lipids in fungal cells can be complemented with ex novo utilization of FFAs secreted from genetically modified Synechocystis strains.

\section{Methods}

\section{Pelletization of $A$. fumigatus cells}

Pelletization was achieved according to [28]. In brief, to achieve pelletization the spore solutions $\left(1.5-2.0 \times 10^{7}\right.$ spores/L) were cultivated at $28{ }^{\circ} \mathrm{C}$ in the liquid fungal growth broth (FGB) containing $3 \mathrm{~g} / \mathrm{L}$ peptone, $0.6 \mathrm{~g} / \mathrm{L}$ $\mathrm{KH}_{2} \mathrm{PO}_{4}, 0.001 \mathrm{~g} / \mathrm{L} \mathrm{ZnSO}, 0.4 \mathrm{~g} / \mathrm{L} \mathrm{K}_{2} \mathrm{HPO}_{4}, 0.005 \mathrm{~g} / \mathrm{L}$ $\mathrm{FeSO}_{4}, 0.5 \mathrm{~g} / \mathrm{L} \mathrm{MnSO}_{4}, 0.5 \mathrm{~g} / \mathrm{L} \mathrm{MgSO}_{4}$. As a carbon source we used $20 \mathrm{~g} / \mathrm{L}$ glucose (A. fumigatus/GLU) or $1 \%$ acid pre-treatment of wheat straw (TWS, A. fumigatus/ TWS) with a shaking speed of $150 \mathrm{rpm}$ for $72 \mathrm{~h}$.

\section{Synechocystis strains}

All Synechocystis PCC 6803 strains were received from Professor Roy Curtiss III Arizona State University and have been described in $[17,35]$. The strains were grown axenically at $25{ }^{\circ} \mathrm{C}$ in BG-11 medium [101] under continuous illumination $\left(250 \mu \mathrm{mol}\right.$ photons $\left.\mathrm{m}^{-2} \mathrm{~s}^{-1}\right)$ and bubbled with $4 \% \mathrm{CO}_{2}$-enriched air. The details for growing SD culture under $\mathrm{CO}_{2}$-enriched and limited conditions were described in [17]. Growth rates were analysed by counting the cell numbers using a $\mathrm{TC} 10^{\mathrm{TM}}$ Automated Cell Counter (BioRad) and by measuring $\mathrm{OD}_{750}$. For biomass analysis SD cultures were centrifuged at $6000 \mathrm{~g}$ and then washed twice with sterile water and centrifuged again and dried at $65^{\circ} \mathrm{C}$. Synechocystis strains were grown in six flasks to a cell density $1.0 \pm 0.8 \times 10^{9}$ (see Additional file 5: Figure S4). From this stage, $(t=0)$, three flasks were mixed with $A$. fumigatus pellets for $24 \mathrm{~h}$ of co-cultivation (A. fumigatus-SD, $\mathrm{t}=24 \mathrm{~h}$ ). Another 3 flasks were continued growing for another $24 \mathrm{~h}$ (control, $t=24 \mathrm{~h}$ ). For 'Green Recovery' experiments strains were grown till $1.0 \pm 0.8 \times 10^{9}$ in six flasks. Three days before mixing with fungal pellets bubbling with $4 \%$ $\mathrm{CO}_{2}$ was stopped in all flasks and they were sealed with plastic wrap and rotated at $100 \mathrm{rpm}$ under continuous illumination. Cell's colour started turning from green to yellow. After 3 days, $(t=0)$, three flasks were mixed with A. fumigatus pellets for $24 \mathrm{~h}$ of co-cultivation ( $A$. fumigatus-SD strains, $t=24 \mathrm{~h}$ ) under $\mathrm{CO}_{2}$ depleted conditions. Another 3 flasks were continued growing for another $24 \mathrm{~h}$ also under $\mathrm{CO}_{2}$ depleted conditions (control, $t=24 \mathrm{~h}$ ).

\section{Fungal-assisted flocculation of SD cells}

Before mixing with Synechocystis strains A. fumigatus pellets were washed by sterile BG11 medium. Synechocystis cultures were precipitated, washed and resuspended till concentration of $1.0 \pm 0.8 \times 10^{9} \mathrm{cell} / \mathrm{mL}$ in BG11. The fungal-SD mixtures were shaken at $150 \mathrm{rpm}$ for $48 \mathrm{~h}$ under constant light $\left(200 \mu \mathrm{mol} \mathrm{m}{ }^{-2} \mathrm{~s}^{-1}\right)$ at $25^{\circ} \mathrm{C}$. Fungal and SD mono-cultures were also grown in BG11 media for $48 \mathrm{~h}$ as controls. All experiments were biologically replicated at least three times. Cell number, biomass and $\mathrm{OD}_{750}$ were measured at time 0,24 and $48 \mathrm{~h}$. Synechocystis cell samples were analysed 3 min after stopping rotation [46]. Flocculation efficiency (FE) was calculated based on changes in OD, cell numbers and in chlorophyll concentrations of uncaptured SD cells in the co-cultivation media at time 0 and $48 \mathrm{~h}$ later according to the following formula: $\mathrm{FE} \%=\frac{A-B}{A} \times 100$, where $A=\mathrm{OD}$, cell number at time $0 ; B=\mathrm{OD}$, cell number after $24 \mathrm{~h}$ after $48 \mathrm{~h} . \mathrm{EF}_{50}$ is represented by amount of $A$. fumigatus (DW) required to flocculate $50 \%$ of SD cells from $100 \mathrm{~mL}$ media containing $1.0 \times 10^{9}$ cells after $48 \mathrm{~h}$. The morphology of the fungal and algal cells and co-cultivation pellets was observed under bright field conditions using a Leica DM 2500 with the attached camera is a Leica DFC 310 FX. 


\section{Nile Red staining}

For Nile Red staining the algal cells, fungal cells and co-cultivated pellets were collected by centrifugation and re-suspended in $1 \mathrm{~mL}$ of $20 \%$ DMSO containing 5 $\mu \mathrm{L}$ of Nile Red stock solution $(0.10 \mathrm{mg} / \mathrm{mL}$ of Nile Red dissolved in acetone) and incubated at $50{ }^{\circ} \mathrm{C}$ with shaking at $150 \mathrm{rpm}$ for $5 \mathrm{~min}$. The stained pellets were then subjected to fluorescent microscopy analysis to observe the formation of lipid droplets in the co-cultivated cells using Leica DM 2500 with an attached camera Leica DFC 310 FX. Nile-Red filter: excitation at $543 \mathrm{~nm}$, emission $555-650 \mathrm{~nm}$.

\section{Lipid yield and fatty acid profile analysis}

Extraction and analysis of lipid yield and FAME composition analysis of algal, fungal and fungal-algal pellets were performed using a method previously described $[19,102]$. Secreted FFAs were separated from the culture medium by hexane according [17, 35]. In brief, $50 \mathrm{~mL}$ of culture was acidified by $1.0 \mathrm{~mL} 1 \mathrm{M} \mathrm{H}_{3} \mathrm{PO}_{4}$ containing $1.0 \mathrm{~g} \mathrm{NaCl}$, and extracted with $25 \mathrm{~mL}$ hexane. Intracellular FFAs and lipids, the cells were extracted by the Folch method [103]. The FFA samples were analyzed by GC [104].

\section{Zeta potential and cell size measurements}

The zeta potential and cell size measurements of cells were obtained using a Nano-ZS/ZEN 3600. The zeta potentials were evaluated at a room temperature of $20 \pm 1{ }^{\circ} \mathrm{C}$. To analyse effect of co-cultivation of Synechocystis and A. fumigatus cells on their surface charges we mixed SD277 with A. fumigatus pellets and after $12 \mathrm{~h}$ $50 \mathrm{ml}$ of co-cultivation media was collected, centrifuged at 10,000 rpm and filtered through $0.22 \mu \mathrm{M}$ filter to remove Synechocystis and fungal cells and spores. To analyse zeta potential values of all components in this cocultivation media, SD277 and A. fumigatus cells growing separately in monocultures were precipitated and resuspended in co-cultivation media. A. fumigatus-SD277 pellets were also analysed submerged in co-cultivation media. For each species, triplicate cultures were taken for measurements and for each data set, 10-20 readings were taken for each sample.

\section{Acid pre-treatment of wheat straw}

One gram of fine powder (approximately $1 \mathrm{~mm}$ sin size) of dry wheat straw was mixed with $1 \mathrm{M}$ sulphuric acid and autoclaved for $10 \mathrm{~min}$ at $121{ }^{\circ} \mathrm{C}$, allowed to cool, filtered through Whatman No. 1 filter paper, then washed by $0.1 \mathrm{M}$ sodium hydroxide followed by 10 times with sterile water. The powder was dried at $80^{\circ} \mathrm{C}$ and added to the media to a final concentration of $1 \%$.

\section{Wastewater treatment}

The anaerobically digested swine lagoon wastewater (ASW) was provided by Dr. J Hill, Termes Consulting Ltd, Melbourne. Swine wastewater was treated anaerobically. Wastewater samples were centrifuged to remove large particles, filtered through Whatman filter paper and autoclaved at $121{ }^{\circ} \mathrm{C}$, allowed to cool to room temperature, and stored at $4{ }^{\circ} \mathrm{C}$. The concentrations of $\mathrm{NH}_{4}{ }^{+}-\mathrm{N}$ and $\mathrm{PO}_{4}^{-3}-\mathrm{P}$ in the ASW were 680.7 and $145.7 \mathrm{mg} / \mathrm{L}$, respectively. The concentration of other inorganic nitrogen in the wastewater, such as $\mathrm{NO}_{3}{ }^{-}-\mathrm{N}$ was very low and not reported. Wastewater was diluted to 25 and $10 \%$ with tap water. The fungal and fungal-SD pellets were harvested by filtration and 200 wet pellets were added to the $250 \mathrm{~mL}$ of wastewater (approximately, $1 \mathrm{~g} / \mathrm{L} \mathrm{DW}$ ). The mixtures were shaken at $150 \mathrm{rpm}$ for $48 \mathrm{~h}$. Samples of growth media were analyzed for ammonia cations, nitrate and phosphate anions using an ion chromatography system Dionex ICS-1100 (Thermo Scientific, USA).

\section{Environmental scan electron microscopy analysis}

For environmental scanning electron microscopy the samples were first dehydrated using gradual ethanol concentration starting from 10 to $100 \%$. Samples were soaked in ethanol concentration for $10 \mathrm{~min}$ before being transferred into higher concentration at room temperature. Dehydrated samples were subjected to the critical point dry facility for $10 \mathrm{~min}$. The dried samples then allowed to gold coating for $60 \mathrm{~s}$ before the images were captured using FEI Quanta 200 SEM using environmental detector.

\section{Statistical analysis}

All experiments in this study were conducted in triplicate. All data are expressed as mean \pm standard deviation. The experimental data were subjected to the one-way analysis of variance (ANOVA) as implemented in the GraphPad InStat 3 statistics platform. Tukey simultaneous tests were conducted to determine the statistical differences between treatments. In order to ascertain that the observed variations in growth rates, efficiency of nutrients uptake and the yield of pyrolysis products were statistically significant, the probability $(P)$ values were determined. A $95 \%$ confidence level $(P<0.05)$ was applied for all analyses. 


\section{Additional files}

Additional file 1: Figure S1. Artistic representation of two strategies designed for secretion of FFAs to growth media:'FFA Secretion' and 'Green Recovery'from Synechocystis PCC 6803 cells. Text in red represents genetic modifications of SD100 strains.

Additional file 2: Table S1. Description of plasmids and genotypes of wild-type and genetically modified Synechocystis PCC 6803 strains. For more detailed description see [17, 35].

Additional file 3: Figure S2. Pelletization of A. fumigatus grown in liquid media. (A) A. fumigatus pellets grown on FGB with no extra carbon source (left); with 1\% TWS (middle) and with 20\% glucose (right); (B) A. fumigatus pellets grown on FGB with $20 \%$ glucose (viewed from bottom); (C) A. fumigatus pellets grown on FGB with 20\% glucose (left) and with 1\% TWS (right). Scale $=5 \mathrm{~mm}$.

Additional file 4: Figure S3. Biomass production and lipid yields of A. fumigatus growing on different carbon sources. A. fumigatus $/ N E C$ : $A$. fumigatus grown on FGB with no extra carbon source; $A$. fumigatus/GLU: $A$. fumigatus grown on FGB with $20 \%$ glucose; A. fumigatus/TWS: A. fumigatus grown on FGB with $1 \%$ TWS. Significance levels: $\left.\left.{ }^{*}\right) p<0.05 ;{ }^{*}\right) p<0.01$.

Additional file 5: Figure S4. Representation of flocculation experiments with 'FFA Secretion' (1) and 'Green recovery' (2) strains.

Additional file 6: Figure S5. Evaluation of Synechocystis PCC 6803 growth rates in the media containing $5 \%$ and $20 \%$ of A. fumigatus/TWS media. (A) BG11 growth media containing 5\% of A. fumigatus/TWS media; B) BG11 growth media containing 20\% A. fumigatus/TWS media.

Additional file 7: Figure S6. Environmental scanning electron microscopy of A. fumigatus and A. fumigatus-Synechocystis PCC 6803 associations. $(\mathrm{A}, \mathrm{B})$ A. fumigatus pellets growing in liquid media; (C) A. fumigatus-SD100 and (D) A. fumigatus-SD216 pellets.

Additional file 8: Figure S7. Increase in biomass and lipid/Intracellular FFA yield in A. fumigatus-Synechocystis pellets after flocculation. (A) Increase in lipids in A. fumigatus/GLU-SD pellets compare to the additive yields of lipid/intracellular FFA and extracellular FFAs extracted from mono-cultured A. fumigatus and SD strains before co-cultivation. (B) Increase in lipids in A. fumigatus/TWS-SD pellets compare to the additive yields of lipid/intracellular FFAs and extracellular FFAs extracted from mono-cultured A. fumigatus and SD strains before co-cultivation. Significance levels: $\left.\left.{ }^{*}\right) \mathrm{p}<0.05{ }^{* *}\right) \mathrm{p}<0.01$.

Additional file 9: Figure S8. The samples of A. fumigatus-SD100, A. fumigatus-SD256 and A. fumigatus-SD257 pellets. 1) A. fumigatus-SD100 (left), A. fumigatus-SD256 after $\mathrm{CO}_{2}$ limitation (right); 2) A. fumigatus-SD100 (left), A. fumigatus-SD257 after $\mathrm{CO}_{2}$ limitation (right).

Additional file 10: Figure S9. Application of A. fumigatus-SD100 pellets for $25 \%$ swine wastewater treatment. (1) $25 \%$ swine wastewater at $\mathrm{t}=0$ and $48 \mathrm{~h}$ after treatment with SD100 (2); A. fumigatus (3) and A. fumigatusSD (4). Tap water as control (5).

\section{Abbreviations}

A. fumigatus: Aspergillus fumigatus; ACP: acyl-acyl carrier protein; C. camphorum: Cinnamomum camphorum; C. hookeriana: Cuphea hookeriana; C: carbon; DAG: diacylglycerols; $\mathrm{FE}_{50}$ : half maximal flocculation efficiencies; FFA: free fatty acids; GLU: glucose; N: nitrogen; NEC: no extra carbon; P: phosphate; SWW: swine wastewater; TAG: triacylglycerols; TE: thioesterases; TWS: treated wheat straw; U. californica: Umbellularia californica.

\section{Authors' contributions}

AM designed the project and conducted the large part of the biotechnological experiments, was involved in interpretation of data for the work, made substantial contributions in writing a manuscript, and approved the final version for publication. AFM was involved in growing Synechocystis and fungal strains, co-pelletization experiments, analyzing their biomass and growth rates, contributing to the statistical analysis of generated data and revising the manuscript. DW was involved in growing co-pelletization experiments, analyzing lipid and FFAs level and composition, contributing to the statistical analysis of generated data and revising the manuscript. PM was involved in extracting lipids and FFAs, analysing their level and compositions and writing and revising the manuscript. MT was involved in growing fungal strains, measuring zeta potentials and helped to revise the manuscript. TS made contributions to interpretation of data for the work, helped to draft the manuscript and approved the final version for publication. ASB participated in experimental design and helped to draft the manuscript. All authors read and approved the final manuscript.

\section{Acknowledgements}

We are sincerely thankful to Professor Roy Curtiss IIIrd from a Center for Infectious Diseases and Vaccinology, Arizona State University for providing us with the Synechocystis sp. PCC6803 strains and plasmids. This work was supported by the College of Science, Engineering and Health and the School of Applied Sciences of Royal Melbourne Institute of Technology University. The authors also thank Dr. J Hill, Termes Consulting Ltd, Melbourne for proving anaerobically digested swine wastewater. The authors also thank Bryan Cooke (RMIT University) for fruitful discussions.

\section{Competing interests}

The authors declare that they have no competing interests.

Received: 5 August 2015 Accepted: 22 October 2015

Published online: 05 November 2015

\section{References}

1. Wu YH, Hu HY, Yu Y, Zhang TY, Zhu SF, Zhuang LL, Zhang X, Lu Y. Microalgal species for sustainable biomass/lipid production using wastewater as resource: a review. Renew Sust Energ Rev. 2014;33:675-88.

2. Aguirre AM, Bassi A, Saxena P. Engineering challenges in biodiesel production from microalgae. Crit Rev Biotechnol. 2013;33:293-308.

3. Rajkumar R, Yaakob Z, Takriff MS. Potential of the micro and macro algae for biofuel production: a brief review. Bioresources. 2014;9:1606-33.

4. Schenk PM, Thomas-Hall SR, Stephens E, Marx UC, Mussgnug JH, Posten C, Kruse O, Hankamer B. Second generation biofuels: high-efficiency microalgae for biodiesel production. Bioenerg Res. 2008;1:20-43.

5. Borowitzka MA, Moheimani NR. Sustainable biofuels from algae. Mitig Adapt Strat GI. 2013:18:13-25.

6. Islam MA, Magnusson M, Brown RJ, Ayoko GA, Nabi MN, Heimann K. Microalgal species selection for biodiesel production based on fuel properties derived from fatty acid profiles. Energies. 2013;6:5676-702.

7. Gressel J, van der Vlugt CJB, Bergmans HEN. Environmental risks of large scale cultivation of microalgae: mitigation of spills. Algal Res. 2013:2:286-98.

8. Koksharova OA, Wolk CP. Genetic tools for cyanobacteria. Appl Microbiol Biot. 2002;58:123-37.

9. Machado IMP, Atsumi S. Cyanobacterial biofuel production. J Biotechnol. 2012;162:50-6.

10. Wahlen BD, Willis RM, Seefeldt LC. Biodiesel production by simultaneous extraction and conversion of total lipids from microalgae, cyanobacteria, and wild mixed-cultures. Bioresource Technol. 2011;102:2724-30.

11. Sharma KK, Garg S, Li Y, Malekizadeh A, Schenk PM. Critical analysis of current microalgae dewatering techniques. Biofuels. 2013;4:397-407.

12. Lam MK, Lee KT. Microalgae biofuels: a critical review of issues, problems and the way forward. Biotechnol Adv. 2012;30:673-90.

13. Pinzi S, Leiva-Candia D, Lopez-Garcia I, Redel-Macias MD, Dorado MP Latest trends in feedstocks for biodiesel production. Biofuel Bioprod Bior. 2014;8:126-43.

14. Simas-Rodrigues C, Villela HDM, Martins AP, Marques LG, Colepicolo P, Tonon AP. Microalgae for economic applications: advantages and perspectives for bioethanol. J Exp Bot. 2015:66:4097-108.

15. Albers S, Cheah YE, Peebles C. Towards biofuel production in Synechocystis sp. PCC 6803: expanding the molecular biology toolbox. In: 243rd ACS national meeting \& exposition. San Diego: American Chemistry Society; 2012 
16. Kaiser BK, Carleton M, Hickman JW, Miller C, Lawson D, Budde M, Warrener P, Paredes A, Mullapudi S, Navarro P, et al. Fatty aldehydes in cyanobacteria are a metabolically flexible precursor for a diversity of biofuel products. PLoS One. 2013;8:e58307.

17. Liu X, Fallon S, Sheng J, Curtiss R. CO2-limitation-inducible green recovery of fatty acids from cyanobacterial biomass. Proc Natl Acad Sci USA. 2011;108:6905-8.

18. Sheng J, Kim HW, Badalamenti JP, Zhou C, Sridharakrishnan S, Krajmalnik-Brown R, Rittmann BE, Vannela R. Effects of temperature shifts on growth rate and lipid characteristics of Synechocystis sp PCC6803 in a bench-top photobioreactor. Bioresource Technol. 2011;102:11218-25.

19. Sheng J, Vannela R, Rittrnann BE. Evaluation of methods to extract and quantify lipids from Synechocystis PCC 6803. Bioresource Technol. 2011;102:1697-703.

20. McBride R, Behnke C, Heaps N. Challenges of generating algae biomass at scale for biofuel production. In: 243rd ACS national meeting \& exposition. San Diego: American Chemistry Society; 2012.

21. Borowitzka MA. Marine and halophilic algae for the production of biofuels. J Biotechnol. 2008;136:S7.

22. Sharma KK, Schuhmann H, Schenk PM. High lipid induction in microalgae for biodiesel production. Energies. 2012;5:1532-53.

23. Gultom SO, Hu B. Review of microalgae harvesting via co-pelletization with filamentous fungus. Energies. 2013;6:5921-39.

24. Zhang JG, Hu B. A novel method to harvest microalgae via coculture of filamentous fungi to form cell pellets. Bioresource Technol. 2012;114:529-35.

25. Xie SX, Sun S, Dai SY, Yuan JS. Efficient coagulation of microalgae in cultures with filamentous fungi. Algal Research. 2013;2:28-33.

26. Zhou WG, Cheng YL, Li Y, Wan YQ, Liu YH, Lin XY, Ruan R. Novel fungal pelletization-assisted technology for algae harvesting and wastewater treatment. Appl Biochem Biotech. 2012;167:214-28.

27. Muradov N, Taha M, Miranda AF, Wrede D, Kadali K, Gujar A, Stevenson T, Ball AS, Mouradov A. Fungal-assisted algal flocculation: application in wastewater treatment and biofuel production. Biotechnol Biofuels. 2015;8:4.

28. Wrede D, Taha M, Miranda AF, Kadali K, Stevenson T, Ball AS, Mouradov A. Co-cultivation of fungal and microalgal cells as an efficient system for harvesting microalgal cells, lipid production and wastewater treatment. PLoS One. 2014;9:e113497.

29. Luo SS, Dong ZJ, Wu XD, Liu YH, Ruan R. Pelletization behavior of fungal Chlorella sp. symbiosis system. Res J Biotechnol. 2013;8:56-9.

30. Talukder MMR, Das P, Wu JC. Immobilization of microalgae on exogenous fungal mycelium: a promising separation method to harvest both marine and freshwater microalgae. Biochem Eng J. 2014;91:53-7.

31. Zhou WG, Min M, Hu B, Ma XC, Liu YH, Wang O, Shi J, Chen P, Ruan R. Filamentous fungi assisted bio-flocculation: a novel alternative technique for harvesting heterotrophic and autotrophic microalgal cells. Sep Purif Technol. 2013;107:158-65.

32. Taylor TN, Hass H, Remy W, Kerp H. The oldest fossil lichen. Nature. 1995;378:244

33. Zoller S, Lutzoni F. Slow algae, fast fungi: exceptionally high nucleotide substitution rate differences between lichenized fungi Omphalina and their symbiotic green algae Coccomyxa. Mol Phylogenet Evol. 2003;29:629-40.

34. Ruffing AM, Jones HDT. Physiological effects of free fatty acid production in genetically engineered Synechococcus elongatus PCC 7942. Biotechnol Bioeng. 2012;109:2190-9.

35. Liu XY, Sheng J, Curtiss R. Fatty acid production in genetically modified cyanobacteria. P Natl Acad Sci USA. 2011;108:6899-904.

36. Kim HW, Vannela R, Rittmann BE. Responses of Synechocystis sp. PCC 6803 to total dissolved solids in long-term continuous operation of a photobioreactor. Bioresource Technol. 2013;128:378-84.

37. Liu XY, Curtiss R. Nickel-inducible lysis system in Synechocystis sp. PCC 6803. P Natl Acad Sci USA. 2009;106:21550-4.

38. Quintana N, Van der Kooy F, Van de Rhee MD, Voshol GP, Verpoorte R. Renewable energy from cyanobacteria: energy production optimization by metabolic pathway engineering. Appl Microbiol Biot. 2011:91:471-90.

39. Mullineaux CW. The thylakoid membranes of cyanobacteria: structure, dynamics and function. Aust J Plant Physiol. 1999;26:671-7.
40. Radakovits R, Jinkerson RE, Darzins A, Posewitz MC. Genetic engineering of algae for enhanced biofuel production. Eukaryot Cell. 2010;9:486-501.

41. Rajab AH. Micro-algae removal in domestic wastewater using Aspergillus Flavus soft pellets as a bio-coagulant. Faculty of Engineering: Universiti Putra Malaysia; 2007

42. Henderson RK, Parsons SA, Jefferson B. Successful removal of algae through the control of zeta potential. Sep Sci Technol. 2008;43:1653-66.

43. Holder DJ, Kirkland BH, Lewis MW, Keyhani NO. Surface characteristics of the entomopathogenic fungus Beauveria (Cordyceps) bassiana. Microbiology. 2007;153:3448-57.

44. Selbmann L, Stingele F, Petruccioli M. Exopolysaccharide production by filamentous fungi: the example of Botryosphaeria rhodina. Anton Leeuw Int J G. 2003;84:135-45.

45. Seviour RJ, Stasinopoulos SJ, Auer DPF, Gibbs PA. Production of pullulan and other exopolysaccharides by filamentous fungi. Crit Rev Biotechnol. 1992;12:279-98.

46. Wrede D, Taha M, Miranda AF, Kadali K, Stevenson T, Ball A, Mouradov A. Co-cultivation of fungal and microalgal cells as an efficient system for harvesting microalgal cells, lipid production and wastewater treatment. PLoS One. 2014;9:e113497

47. Papanikolaou S, Aggelis G. Lipids of oleaginous yeasts. Part I: Biochemistry of single cell oil production. Eur J Lipid Sci Tech. 2011;113:1031-51.

48. Munch G, Sestric R, Sparling R, Levin DB, Cicek N. Lipid production in the under-characterized oleaginous yeasts, Rhodosporidium babjevae and Rhodosporidium diobovatum, from biodiesel-derived waste glycerol. Bioresource Technol. 2015:185:49-55.

49. Wang H, Ji CL, Bi SL, Zhou P, Chen L, Liu TZ. Joint production of biodiesel and bioethanol from filamentous oleaginous microalgae Tribonema sp. Bioresource Technol. 2014;172:169-73.

50. Subhash GV, Mohan SV. Biodiesel production from isolated oleaginous fungi Aspergillus sp. using corncob waste liquor as a substrate. Bioresource Technol. 2011;102:9286-90.

51. Zhang GC, French WT, Hernandez R, Hall J, Sparks D, Holmes WE. Microbial lipid production as biodiesel feedstock from $N$-acetylglucosamine by oleaginous microorganisms. J Chem Technol Biot. 2011;86:642-50.

52. Mohan SV, Rohit MV, Chiranjeevi P, Chandra R, Navaneeth B. Heterotrophic microalgae cultivation to synergize biodiesel production with waste remediation: progress and perspectives. Bioresource Technol. 2015;184:169-78.

53. Rismani-Yazdi H, Hampel KH, Lane CD, Kessler BA, White NM, Moats KM, Allnutt FCT. High-productivity lipid production using mixed trophic state cultivation of Auxenochlorella (Chlorella) protothecoides. Bioproc Biosyst Eng. 2015;38:639-50

54. Medipally SR, Yusoff FM, Banerjee S, Shariff M. Microalgae as sustainable renewable energy feedstock for biofuel production. Biomed Res Int. 2015. doi:10.1155/2015/519513.

55. Dillschneider R, Schulze I, Neumann A, Posten C, Syldatk C. Combination of algae and yeast fermentation for an integrated process to produce single cell oils. Appl Microbiol Biot. 2014;98:7793-802.

56. Wang Z, Ma XC, Zhou WG, Min M, Cheng YL, Chen P, Shi J, Wang Q, Liu YH, Ruan R. Oil crop biomass residue-based media for enhanced algal lipid production. Appl Biochem Biotech. 2013;171:689-703.

57. Sharma YC, Singh B, Korstad J. A critical review on recent methods used for economically viable and eco-friendly development of microalgae as a potential feedstock for synthesis of biodiesel. Green Chem. 2011:13:2993-3006

58. Feofilova EP, Sergeeva YE, Ivashechkin AA. Biodiesel-fuel: content, production, producers, contemporary biotechnology (review). Appl Biochem Micro. 2010;46:369-78.

59. Gao CF, Zhai Y, Ding Y, Wu QY. Application of sweet sorghum for biodiesel production by heterotrophic microalga Chlorella protothecoides. Appl Energ. 2010;87:756-61.

60. Chen $\mathrm{CY}$, Zhao XQ, Yen HW, Ho SH, Cheng CL, Lee DJ, Bai FW, Chang JS. Microalgae-based carbohydrates for biofuel production. Biochem Eng J. 2013;78:1-10.

61. John RP, Anisha GS, Nampoothiri KM, Pandey A. Micro and macroalgal biomass: a renewable source for bioethanol. Bioresource Technol. 2011;102:186-93.

62. Webber MM, Webber PJ. Ultrastructure of lichen haustoria: symbiosis in Parmelia sulcata. Can J Bot. 1970:48:1521-4. 
63. Hoiczyk E, Hansel A. Cyanobacterial cell walls: news from an unusual prokaryotic envelope. J Bacteriol. 2000;182:1191-9.

64. Jurgens UJ, Golecki JR, Weckesser J. Characterization of the cell-wall of the unicellular cyanobacterium Synechocystis Pcc-6714. Arch Microbiol. 1985;142:168-74.

65. Pollegioni L, Tonin F, Rosini E. Lignin-degrading enzymes. FEBS J. 2015;282:1190-213.

66. Kumar R, Singh S, Singh OV. Bioconversion of lignocellulosic biomass: biochemical and molecular perspectives. J Ind Microbiol Biot. 2008;35:377-91

67. Bhattacharya AS, Bhattacharya A, Pletschke BI. Synergism of fungal and bacterial cellulases and hemicellulases: a novel perspective for enhanced bio-ethanol production. Biotechnol Lett. 2015;37:1117-29.

68. Druzhinina IS, Shelest E, Kubicek CP. Novel traits of Trichoderma predicted through the analysis of its secretome. FEMS Microbiol Lett. 2012;337:1-9.

69. Van Dyk JS, Pletschke BI. A review of lignocellulose bioconversion using enzymatic hydrolysis and synergistic cooperation between enzymesfactors affecting enzymes, conversion and synergy. Biotechnol Adv. 2012;30:1458-80.

70. Lara-Marquez A, Zavala-Paramo MG, Lopez-Romero E, Camacho HC. Biotechnological potential of pectinolytic complexes of fungi. Biotechnol Lett. 2011;33:859-68.

71. Jayani RS, Saxena S, Gupta R. Microbial pectinolytic enzymes: a review. Process Biochem. 2005;40:2931-44.

72. Browning LM, Walker CG, Mander AP, West AL, Madden J, Gambell JM, Young S, Wang L, Jebb SA, Calder PC. Incorporation of eicosapentaenoic and docosahexaenoic acids into lipid pools when given as supplements providing doses equivalent to typical intakes of oily fish. Am J Clin Nutr. 2012;96:748-58.

73. Cruz-Hernandez C, Oliveira M, Pescia G, Moulin J, Masserey-Elmelegy I, Dionisi F, Destaillats F. Lipase inhibitor orlistat decreases incorporation of eicosapentaenoic and docosahexaenoic acids in rat tissues. Nutr Res. 2010;30:134-40.

74. Guo X, Ota Y. Incorporation of eicosapentaenoic and docosahexaenoic acids by a yeast (FO726A). J Appl Microbiol. 2000;89:107-15.

75. Sridhar R, Lakshminarayana G. Incorporation of eicosapentaenoic and docosahexaenoic acids into groundnut oil by lipase-catalyzed ester interchange. J Am Oil Chem Soc. 1992;69:1041-2.

76. Papanikolaou S, Chevalot I, Komaitis M, Marc I, Aggelis G. Single cell oil production by Yarrowia lipolytica growing on an industrial derivative of animal fat in batch cultures. Appl Microbiol Biot. 2002;58:308-12.

77. Papanikolaou S, Aggelis G. Modeling lipid accumulation and degradation in Yarrowia lipolytica cultivated on industrial fats. Curr Microbiol. 2003;46:398-402.

78. Kohlwein SD, Paltauf F. Uptake of fatty-acids by the yeasts, Saccharomyces-Uvarum and Saccharomycopsis-Lipolytica. Biochim Biophys Acta. 1984;792:310-7.

79. Fickers P, Benetti PH, Wache Y, Marty A, Mauersberger S, Smit MS, Nicaud JM. Hydrophobic substrate utilisation by the yeast Yarrowia lipolytica, and its potential applications. FEMS Yeast Res. 2005;5:527-43.

80. Aggelis G, Papadiotis G, Komaitis M. Microbial fatty acid specificity. Folia Microbiol. 1997:42:117-20.

81. Li Q, Du W, Liu DH. Perspectives of microbial oils for biodiesel production. Appl Microbiol Biot. 2008;80:749-56.

82. Lennen RM, Pfleger BF. Microbial production of fatty acid-derived fuels and chemicals. Curr Opin Biotech. 2013;24:1044-53.

83. Steen EJ, Kang YS, Bokinsky G, Hu ZH, Schirmer A, McClure A, del Cardayre SB, Keasling JD. Microbial production of fatty-acid-derived fuels and chemicals from plant biomass. Nature. 2010;463:559-U182.

84. Beopoulos A, Chardot T, Nicaud JM. Yarrowia lipolytica: a model and a tool to understand the mechanisms implicated in lipid accumulation. Biochimie. 2009;91:692-6.

85. Calvo AM, Hinze LL, Gardner HW, Keller NP. Sporogenic effect of polyunsaturated fatty acids on development of Aspergillus spp. Appl Environ Microb. 1999;65:3668-73.

86. Calvo AM, Gardner HW, Keller NP. Genetic connection between fatty acid metabolism and sporulation in Aspergillus nidulans. J Biol Chem. 2001;276:25766-74.

87. Faergeman NJ, DiRusso CC, Elberger A, Knudsen J, Black PN. Disruption of the Saccharomyces cerevisiae homologue to the murine fatty acid transport protein impairs uptake and growth on long-chain fatty acids. J Biol Chem. 1997;272:8531-8.

88. Zhang FZ, Rodriguez S, Keasling JD. Metabolic engineering of microbial pathways for advanced biofuels production. Curr Opin Biotech. 2011;22:775-83.

89. Ratledge C. Fatty acid biosynthesis in microorganisms being used for single cell oil production. Biochimie. 2004;86:807-15.

90. Blazeck J, Hill A, Liu LQ, Knight R, Miller J, Pan A, Otoupal P, Alper HS. Harnessing Yarrowia lipolytica lipogenesis to create a platform for lipid and biofuel production. Nat Commun. 2014;5:3131. doi:10.1038/ ncomms4131.

91. Price MS, Classen JJ, Payne GA. Aspergillus niger absorbs copper and zinc from swine wastewater. Bioresource Technol. 2001;77:41-9.

92. Swami D, Buddhi D. Removal of contaminants from industrial wastewater through various non-conventional technologies: a review. Int J Environ Pollut. 2006;27:324-46.

93. Sharma P, Kaur H, Sharma M, Sahore V. A review on applicability of naturally available adsorbents for the removal of hazardous dyes from aqueous waste. Environ Monit Assess. 2011;183:151-95.

94. Abdel-Raouf N, Al-Homaidan AA, Ibraheem IBM. Microalgae and wastewater treatment. Saudi J Biol Sci. 2012;19(3):257-75.

95. Balasubramanian L, Subramanian G, Nazeer TT, Simpson HS, Rahuman ST, Raju P. Cyanobacteria cultivation in industrial wastewaters and biodiesel production from their biomass: a review (retracted article. See vol 59, pg. 153, 2012). Biotechnol Appl Bioc. 2011;58:220-5.

96. Bhatt NC, Panwar A, Bisht TS, Tamta S. Coupling of algal biofuel production with wastewater. Sci World J. 2014. doi:10.1155/2014/210504.

97. Brennan $L$, Owende P. Biofuels from microalgae - a review of technologies for production, processing, and extractions of biofuels and co-products. Renew Sust Energ Rev. 2010;14:557-77.

98. Gong YM, Jiang ML. Biodiesel production with microalgae as feedstock: from strains to biodiesel. Biotechnol Lett. 2011;33:1269-84.

99. Klinthong $\mathrm{W}$, Yang $\mathrm{YH}$, Huang $\mathrm{CH}$, Tan CS. A review: microalgae and their applications in $\mathrm{CO}_{2}$ capture and renewable energy. Aerosol Air Qual Res. 2015;15:712-42.

100. Hollinshead WD, Varman AM, You L, Hembree Z, Tang YJ. Boosting d-lactate production in engineered cyanobacteria using sterilized anaerobic digestion effluents. Bioresource Technol. 2014;169:462-7.

101. Rippka R, Deruelles J, Waterbury JB, Herdman M, Stanier RY. Generic assignments, strain histories and properties of pure cultures of cyanobacteria. J Gen Microbiol. 1979;111:1-61.

102. O'Fallon JV, Busboom JR, Nelson ML, Gaskins CT. A direct method for fatty acid methyl ester synthesis: application to wet meat tissues, oils, and feedstuffs. J Anim Sci. 2007;85:1511-21.

103. Folch J, Lees M, Stanley GHS. A simple method for the isolation and purification of total lipides from animal tissues. J Biol Chem. 1957;226:497-509.

104. Lalman JA, Bagley DM. Extracting long-chain fatty acids from a fermentation medium. J Am Oil Chem Soc. 2004;81:105-10.

\section{Submit your next manuscript to BioMed Central and take full advantage of:}

- Convenient online submission

- Thorough peer review

- No space constraints or color figure charges

- Immediate publication on acceptance

- Inclusion in PubMed, CAS, Scopus and Google Scholar

- Research which is freely available for redistribution

Submit your manuscript at

www.biomedcentral.com/submit
( Biomed Central 